\title{
Estimates of anthropogenic carbon uptake from four three-dimensional global ocean models
}

\author{
James C. Orr, ${ }^{1,2}$ Ernst Maier-Reimer, ${ }^{3}$ Uwe Mikolajewicz, ${ }^{3}$ Patrick Monfray, ${ }^{1,2}$ \\ Jorge L. Sarmiento, ${ }^{4}$ J. R. Toggweiler, ${ }^{5}$ Nicholas K. Taylor, ${ }^{6}$ Jonathan Palmer, ${ }^{6}$ \\ Nicolas Gruber, ${ }^{7,8}$ Christopher L. Sabine, ${ }^{9,10}$ Corinne Le Quéré, ${ }^{4,11}$ Robert M. \\ $\mathrm{Key},{ }^{9}$ and Jacqueline Boutin, ${ }^{12,2}$
}

Abstract. We have compared simulations of anthropogenic $\mathrm{CO}_{2}$ in the four threedimensional ocean models that participated in the first phase of the Ocean Carbon-Cycle Model Intercomparison Project (OCMIP), as a means to identify their major differences. Simulated global uptake agrees to within $\pm 19 \%$, giving a range of $1.85 \pm 0.35 \mathrm{Pg} \mathrm{C} \mathrm{yr}^{-1}$ for the 1980-1989 average. Regionally, the Southern Ocean dominates the present-day air-sea flux of anthropogenic $\mathrm{CO}_{2}$ in all models, with one third to one half of the global uptake occurring south of $30^{\circ} \mathrm{S}$. The highest simulated total uptake in the Southern Ocean was $70 \%$ larger than the lowest. Comparison with recent data-based estimates of anthropogenic $\mathrm{CO}_{2}$ suggest that most of the models substantially overestimate storage in the Southern Ocean; elsewhere they generally underestimate storage by less than $20 \%$. Globally, the OCMIP models appear to bracket the real ocean's present uptake, based on comparison of regional data-based estimates of anthropogenic $\mathrm{CO}_{2}$ and bomb ${ }^{14} \mathrm{C}$. Column inventories of bomb ${ }^{14} \mathrm{C}$ have become more similar to those for anthropogenic $\mathrm{CO}_{2}$ with the time that has elapsed between the Geochemical Ocean Sections Study (1970s) and World Ocean Circulation Experiment (1990s) global sampling campaigns. Our ability to evaluate simulated anthropogenic $\mathrm{CO}_{2}$ would improve if systematic errors associated with the data-based estimates could be provided regionally.

\footnotetext{
${ }^{1}$ Laboratoire des Sciences du Climat de l'Environnement, CEACNRS, Gif-sur-Yvette, France.

${ }^{2}$ Institut Pierre Simon Laplace (IPSL), Paris.

${ }^{3}$ Max Planck Institut für Meteorologie (MPI), Hamburg, Germany.

${ }^{4}$ Atmospheric and Oceanic Sciences (AOS) Program, Princeton University, Princeton, New Jersey.

${ }^{5}$ Geophysical Fluid Dynamics Lab. (GFDL)/NOAA Princeton, New Jersey.

${ }^{6}$ Hadley Centre for Climate Prediction and Research, Meteorological Office, Bracknell, England, United Kingdom.

${ }^{7}$ Physics Institute, University of Bern, Bern, Switzerland.

${ }^{8}$ Now at AOS Program, Princeton University, Princeton, New Jersey.

${ }^{9}$ Department of Geosciences, Princeton University, Princeton, New Jersey.

${ }^{10}$ Now at Joint Institute for the Study of Atmosphere and Ocean (JSAO), University of Washington, c/o NOAA/PMEL, 7600 Sand Point Way NE, Seattle.

${ }^{11}$ Now at Max-Planck-Institut für Biogeochemie, Jena, Germany.

${ }^{12}$ Laboratoire Océanographie Dynamique et de Climatologie (LODyC), Université Pierre et Marie Curie, Paris.
}

Copyright 2001 by the American Geophysical Union.

Paper number 2000GB001273.

0886-6236/01/2000GB001273\$12.00

\section{Introduction}

Since preindustrial time, air-to-sea $\mathrm{CO}_{2}$ fluxes have become more positive everywhere owing to increasing atmospheric $\mathrm{CO}_{2}$. This perturbation to the natural system, termed anthropogenic $\mathrm{CO}_{2}$, is difficult to measure directly in the ocean. Ocean models have been one of the principal tools used to estimate how air-sea fluxes and ocean storage of anthropogenic $\mathrm{CO}_{2}$ have changed. Such models also offer the only means to estimate future change. Today there are numerous ocean models, the most sophisticated of which describe ocean circulation globally in three dimensions and include pertinent equations for carbon and other passive tracers.

Such models have been compared only in regards to their global uptake estimates [Schimel et al., 1995; Siegenthaler and Sarmiento, 1993; Orr, 1993]. More detailed comparison has been hampered by the different protocols that have been used for both modeling and analysis by the different modeling groups. Thus even if models agree on a global scale, it has been difficult to explore regional differences and to determine if global uptake estimates are robust. To improve that situation, the Ocean Carbon-Cycle Model Intercomparison Project (OCMIP) was initiated by the International Geosphere-Biosphere Program (IGBP) through the activity 
known as the Global Analysis, Interpretation and Modeling Task Force (GAIM). OCMIP began in 1995 to compare standard simulations from four three-dimensional (3-D) models from (1) the Max Planck Institut für Meteorologie (MPI, Germany), (2) Princeton University and Geophysical Fluid Dynamics Laboratory (Princeton/GFDL, United States), (3) the Hadley Centre (U.K. Meteorological Office), and (4) the Institute Pierre Simon Laplace (IPSL, France). For consistency, during the first phase of comparison (1995-1997), OCMIP provided standard boundary conditions, protocols, and centralized analysis.

The focus of OCMIP has been on carbon. Here we report on results of comparisons of simulations for anthropogenic $\mathrm{CO}_{2}$. OCMIP simulations for the natural carbon cycle are described elsewhere [Sarmiento et al., 2000]. Additionally, during OCMIP, data-based estimates were used to evaluate model behavior. Modelers refer to model-data comparison as validation, regardless of resulting model performance. Typically, global ocean carbon-cycle models have been validated by comparing simulated versus measured radiocarbon [Maier-Reimer and Hasselmann, 1987; Toggweiler et al., 1989a,b].

During OCMIP, we also made ${ }^{14} \mathrm{C}$ simulations and compared results to bomb and natural ${ }^{14} \mathrm{C}$ deduced from ocean measurements [Broecker et al., 1995]. The natural component of ${ }^{14} \mathrm{C}$ has previously been used to evaluate deep ocean circulation fields simulated by the four OCMIP models [Orr, $1999 \mathrm{a}, \mathrm{b}]$. Here we have focused on bomb ${ }^{14} \mathrm{C}$, a recent transient tracer that is used to evaluate a model's near-surface circulation fields. We also investigated the resemblance between distributions of bomb ${ }^{14} \mathrm{C}$ and anthropogenic $\mathrm{CO}_{2}$ [Siegenthaler and Sarmiento, 1993] and how that changes with time. Finally, we have directly compared our results with recent data-based estimates of anthropogenic $\mathrm{CO}_{2}$ in the ocean.

\section{Methods}

\subsection{Models}

We compare four general circulation models (GCMs): Hadley [Taylor, 1995], IPSL [Delecluse, 1994; Madec and Imbard, 1996; Aumont et al., 1999], MPI [Maier-Reimer, 1993; Maier-Reimer et al., 1993], and Princeton/GFDL [Sarmiento et al., 1995; Murnane et al., 1999]. All four GCMs are three-dimensional and global in nature. Each GCM was designed to simulate realistic large-scale patterns of the general circulation of the ocean. However, models differ because they were designed at different times by different groups with different objectives and constraints.

Table 1 provides a list of some of the principal model differences. All four models discretize the globe into a threedimensional network of grid cells. However, the number of grid cells varies, from tens of thousands for Princeton/GFDL to nearly a million for IPSL. Horizontal grid size varies most among models near the equator, by about a factor of 10 (from $0.5^{\circ}$ to $4.5^{\circ}$, latitudinally). Vertically, models use from 12 to 30 layers to discretize the entire water column; models use from 2 to 10 layers for the surface $100 \mathrm{~m}$. Many other fac-

Table 1. Some Differences Among OCMIP-1 Models

\begin{tabular}{|c|c|c|c|c|}
\hline Item & Princeton/GFDL & MPI & IPSL & Hadley \\
\hline Model, type ${ }^{\mathrm{a}}$ & PE (MOM1) & LSG & PE (OPA7) & $\mathrm{PE}(\mathrm{B}-\mathrm{C})$ \\
\hline Model, run & On-line & Off-line & Off-line & On-line \\
\hline Grid, horizontal & $96 \times 40$ & $72 \times 72$ & $180 \times 150$ & $96 \times 72$ \\
\hline Grid, vertical & 12 & 22 & 30 & 20 \\
\hline Grid, structure ${ }^{b}$ & $\mathbf{B}$ & $\mathbf{E}$ & C & B \\
\hline Grid, rectangular & yes & no & no & yes \\
\hline Forcing & prognostic & prognostic & semi-diagnostic & prognostic \\
\hline Numerics (accuracy) & 1st, 2nd & $1 \mathrm{st}$ & 2nd & 1st, 2nd \\
\hline Free surface & no & yes & no & no \\
\hline Advection scheme ${ }^{c}$ & CTCS & Upstream & MPDATA & CTCS \\
\hline Seasonality & no & yes & yes & yes \\
\hline Diffusion, vertical $^{d}$ & explicit & $\begin{array}{l}\text { numerical } \\
\text { texplicit }\end{array}$ & $\begin{array}{l}\text { TKE } \\
\text { (1.5 order) }\end{array}$ & $\begin{array}{l}\text { KT-ML+Ri } \\
\text { +explicit }\end{array}$ \\
\hline $\begin{array}{l}\text { Diffusion, horizontal } \\
\text { Isopycnal mixing }\end{array}$ & $1000-5000 \mathrm{~m}^{2} \mathrm{~s}^{-1}$ & Numerical & $2000 \mathrm{~m}^{2} \mathrm{~s}^{-1}$ & $80 \mathrm{~m}^{2} \mathrm{~s}^{-1}$ \\
\hline Isopycnal mixing & no & no & no & Redi [1982] \\
\hline
\end{tabular}

\footnotetext{
a Model, type: PE=Primitive Equation model; MOM1=Modular Ocean Model from GFDL, version 1; LSG=Large-Scale Geostrophic model from MPI; OPA7=Océan Parallelisé (version 7) from Laboratoire d'Océanographie Dynamique et de Climatologie; B-C=Bryan and Cox [1972] model.

${ }^{b}$ Grid, structure: designation according to Arakawa [1972]

${ }^{\mathrm{c}}$ Advection scheme: CTCS = Centered in time, centered in space (leapfrog) scheme from Bryan [1969]; MPDATA=multidimensional positive definite advection transport algorithm from Smolarkiewicz and Clark [1986]

dDiffusion, vertical: TKE=prognostic model based on the equations of turbulent kinetic energy proposed by Gaspar et al. [1990] and adapted to OPA by Blanke and Delecluse [1993]; KT-ML+Ri= Mixed layer model from Kraus and Turner [1967] combined with Richardson number dependent diffusion below the mixed layer.
} 
tors also differ. Differences include coordinate systems, numerics, advection schemes, and methods used to account for air-sea fluxes of heat and water. Additionally, models differ in their descriptions of subgrid-scale mixing, isopycnal mixing, turbulent mixing in the surface boundary layer, as well as their basic equations describing ocean circulation.

Simulated results are known to be sensitive to some of these model differences. For example, changing the vertical eddy diffusion coefficient, specified a priori in the GFDL model, has dramatic results on ocean circulation and the distribution of natural ${ }^{14} \mathrm{C}$ [Toggweiler et al., 1989a]. Horizontal eddy diffusion as well as parameterizations of isopycnal mixing and subgrid-scale eddies are crucial to modeling tracers [Danabasoglu et al., 1994; England and Hirst, 1997; England and Rahmstorf, 1999]. The choice of advection scheme, a tradeoff between numerical precision and cost, is important with passive tracers such as anthropogenic $\mathrm{CO}_{2}$ and bomb ${ }^{14} \mathrm{C}$ (J. C. Orr and O. Marti, Modeling ocean CO2 uptake: Advection matters, submitted to Ocean Modelling, 2000). A seemingly small numerical detail such as the relative position of tracer and velocity grid points also causes important differences [Yin and Fung, 1991; Marti et al., 1992].

\subsection{Boundary Conditions and Protocols}

For OCMIP, all modeling groups used a standard set of geochemical boundary conditions in order that model output would be comparable. Within the ocean, all four models transport any passive tracer such as carbon (C) according to the conservation equation

$$
\frac{\partial C}{\partial t}=\mathbf{v} \cdot \nabla C-\nabla(\kappa \nabla C)+J
$$

which describes the rate of change of $\mathrm{C}$ as a function of advection, diffusion, and the effect due to sources minus sinks $J$, respectively. Here $\mathbf{v}$ is the velocity vector, and $\kappa$ is the diffusion tensor. For our simulations, the final term is nonzero only for ${ }^{14} \mathrm{C}$, where it represents an interior sink due to radioactive decay

$$
J=-\lambda C \text {. }
$$

For ${ }^{14} \mathrm{C}, \lambda$ is the decay rate represented by its half-life $\left(t_{1 / 2}=5730\right.$ years $)$; for $\mathrm{CO}_{2}$, which is almost entirely ${ }^{12} \mathrm{C}$ and ${ }^{13} \mathrm{C}, \lambda=0$.

We also accounted for the surface boundary conditions due to air-sea $\mathrm{CO}_{2}$ gas exchange. In practice, this amounts to accounting for the related surface level change in $\partial C / \partial t$, i.e., adding to the right-hand side of (1), in the surface level only, the following term:

$$
\frac{F}{\Delta z_{1}}
$$

where $F$ is the air-sea carbon flux and $\Delta z_{1}$ is the depth of the first layer.

We determined the air-sea $\mathrm{CO}_{2}$ flux $\mathrm{F}$ as

$$
F=K_{g}\left(p \mathrm{CO}_{2 a}-p \mathrm{CO}_{2 o}\right)(1-I),
$$

where $K_{g}$ is the gas transfer coefficient (mol C m${ }^{-2} \mathrm{yr}^{-1}$ $\left.\mu \mathrm{atm}^{-1}\right), p \mathrm{CO}_{2 a}$ and $p \mathrm{CO}_{2 o}$ are the partial pressures of $\mathrm{CO}_{2}$ in the atmosphere and ocean ( $\mu \mathrm{atm})$, and $I$ is the fractional sea ice cover, which varies between 0 and 1 . Climatological monthly two-dimensional (2-D) fields of $K_{g}$ were determined from solubilities and remotely sensed winds (Appendix). Most of the models simulated preindustrial conditions by fixing atmospheric $\mathrm{CO}_{2}$ to $278 \mu$ atm and integrating simulations until reaching a steady state: the Hadley model $\mathrm{CO}_{2}$ simulations were abiotic; the MPI and Princeton/GFDL model simulations also considered effects due to ocean biota [Sarmiento et al., 2000]. However, changes in ocean biota are generally considered to play little if any role in ocean uptake of anthropogenic $\mathrm{CO}_{2}$ [Murnane et al., 1999]. The fourth model, from IPSL, simulated only anthropogenic $\mathrm{CO}_{2}$, abiotically, following the perturbation approach of Sarmiento et al. [1992]. For anthropogenic $\mathrm{CO}_{2}$, all four models prescribed atmospheric $\mathrm{CO}_{2}$ to follow the observed record between 1765 and 1990, obtained from a spline fit to Mauna Loa plus ice core data [Enting et al., 1994]. Atmospheric $\mathrm{CO}_{2}$ after 1990 was also prescribed, following IPCC stabilization scenario S450 [Enting et al., 1994].

To model ${ }^{14} \mathrm{C}$, we treated the ${ }^{14} \mathrm{C} /{ }^{12} \mathrm{C}$ ratio as a concentration, replacing $C$ in (1), and we neglected effects due to fractionation (due to biology and to a lesser extent gas exchange). Modeled results are thus directly comparable to the fractionation-corrected measurements which are reported as $\Delta{ }^{14} \mathrm{C}$ [Toggweiler et al., 1989a]. Regarding our neglect of fractionation, Bacastow and Maier-Reimer [1990] showed that accounting for biological effects did not affect simulated results for natural ${ }^{14} \mathrm{C}$, as long as the atmospheric $\mathrm{CO}_{2}$ boundary condition for $\mathrm{CO}_{2}$ was identical in both cases, with and without biology. For bomb ${ }^{14} \mathrm{C}$, the neglect of biological fractionation induces a relatively small simulation error [Joos et al., 1997].

For the ${ }^{14} \mathrm{C}$ flux, we essentially followed the Toggweiler et al. [1989a] approach and treated the surface boundary condition (equation (3)) as the air-sea difference in the ${ }^{14} \mathrm{C}^{12} \mathrm{C}$ ratio times the normalized rate of replenishment of the $\mathrm{CO}_{2}$ in the upper layer due to gas exchange $(\mu)$, so that

$$
\frac{F}{\Delta z_{1}}=\mu\left(C_{a}-C_{o}\right)(1-I) .
$$

Here $C_{a}$ is the atmospheric ratio (held to $0 \%$ for natural ${ }^{14} \mathrm{C}$ ) and $C_{o}$ is the oceanic ratio, as simulated in each surface grid box of the ocean model. In the model, levels of ${ }^{14} \mathrm{C}$ are not carried directly in permil but as a percent depletion relative to the atmosphere. Thus the atmosphere is held at 100 (for natural ${ }^{14} \mathrm{C}$ ) and the ocean is initialized to 85 everywhere (equivalent to $-150 \%$, the global mean in natural ${ }^{14} \mathrm{C}$ as determined from the Geochemical Ocean Sections Study (GEOSECS)). Units in permil are obtained using $\Delta^{14} C=10 \times\left(C_{\text {model }}-100\right)$.

For the air-sea transfer, the normalized rate (in $\mathrm{yr}^{-1}$ ) at which $\mathrm{CO}_{2}$ is replenished is 
Table 2. Global Anthropogenic $\mathrm{CO}_{2}$ Uptake (1980-1989) and Bomb ${ }^{14} \mathrm{C}$ Penetration Depth

\begin{tabular}{lccc}
\hline & $\begin{array}{c}\text { Uptake, } \\
\text { Model }\end{array}$ & \multicolumn{2}{c}{ GEOSECS Mean Bomb ${ }^{14}$ C Penetration Depth, m } \\
\cline { 3 - 4 } & Pg Cyr $^{-1}$ & Mean Inv./Surf. Conc. & Mean of all Stations \\
\hline Princeton/GFDL & 2.2 & 312 & 375 \\
Hadley & 2.1 & 314 & 376 \\
MPI & 1.6 & 313 & 353 \\
IPSL & 1.5 & 275 & 283 \\
Observations $^{b}$ & & & 390 \\
\hline
\end{tabular}

a Area-weighted mean from all grid boxes in the GEOSECS composite map: Atlantic in 1973.0, Pacific in 1974.0, and Indian in 1978.0

bFrom Broecker et al. [1995]

$$
\mu=\frac{K_{g} p \mathrm{CO}_{2 a}}{\mathrm{DIC}_{s} \Delta z_{1}}
$$

where $\mathrm{DIC}_{s}$ is the surface ocean concentration of dissolved inorganic carbon (taken as $2.0 \mathrm{~mol} \mathrm{~m}^{-3}$ [Toggweiler et al., $1989 \mathrm{a}]), p \mathrm{CO}_{2 a}$ is atmospheric $p \mathrm{CO}_{2}(278 \mu \mathrm{atm}$ for natural ${ }^{14} \mathrm{C}$ ), and $K_{g}$ is the gas transfer coefficient (in units of mol $\mathrm{C} \mathrm{m}^{-2} \mathrm{yr}^{-1} \mu \mathrm{atm}^{-1}$ ) computed as for $\mathrm{CO}_{2}$ (Appendix).

To simulate oceanic ${ }^{14} \mathrm{C}$ during the industrial era, we forced all models to follow historical estimates of atmospheric ${ }^{14} \mathrm{C} /{ }^{12} \mathrm{C}$ from 1839 to 1995 , as given by Enting et al. [1994] for three latitudinal bands: $90^{\circ}-20^{\circ} \mathrm{S}, 20^{\circ} \mathrm{S}-20^{\circ} \mathrm{N}$, and $20^{\circ}-90^{\circ} \mathrm{N}$. Simultaneously, we increased the $p \mathrm{CO}_{2 a}$ from 1765 to 1995 , as described previously for the anthropogenic $\mathrm{CO}_{2}$ simulation. Thus our approach for ${ }^{14} \mathrm{C}$ also accounts for anthropogenic changes in atmospheric $\mathrm{CO}_{2}$, unlike Toggweiler et al. [1989b], who kept atmospheric $\mathrm{CO}_{2}$ at the preindustrial level. For the gap between 1765 and 1839, atmospheric ${ }^{14} \mathrm{C}$ was held to its preindustrial value of $0 \%$. During analysis, we arbitrarily defined the bomb ${ }^{14} \mathrm{C}$ component as the change from the mean state in 1954 to the mean for a given year in the nuclear era. By definition, this "bomb" component also includes changes due to the Suess effect.

\section{Model Comparison}

The range of estimates of global uptake of anthropogenic $\mathrm{CO}_{2}$ during the 1980s from the four OCMIP-1 models is 1.5-2.2 $\mathrm{Pg} \mathrm{Cyr}^{-1}$ (Table 2). Relative differences between models remain similar throughout the historical period. The 1980-1989 range falls within the spread of flux estimates from previous compilations of 1-D, 2-D, and 3-D global ocean model results: $2.0 \pm 0.8 \mathrm{Pg} \mathrm{Cyr}^{-1}$ [Watson et al., 1990 ; Schimel et al., 1995], 2.0 $0.6 \mathrm{Pg} \mathrm{Cyr}^{-1}$ [Siegenthaler and Sarmiento, 1993], and 2.0 $\pm 0.5 \mathrm{PgC} \mathrm{yr}^{-1}[O r r, 1993]$. Thus the ranges from previous work are wider than found in this study. Unlike earlier comparisons, we do not include estimates from 1-D and 2-D models, nor do we assign additional uncertainty due to our imperfect understanding of the global distribution of bomb ${ }^{14} \mathrm{C}$. One typically adjusts $1-D$ and 2-D models to match the global distribution of bomb ${ }^{14} \mathrm{C}$. Thus uncertainties for ${ }^{14} \mathrm{C}$ affect estimates of anthropogenic $\mathrm{CO}_{2}$ uptake from such models. In contrast, 3-D models are more complex and not easy to adjust to observed tracer distributions. Thus in 3-D models, ocean tracer distributions are typically used only as evaluation tools.

Regional uptake patterns are grossly similar among models. Ocean uptake is highest in the high latitudes and at the equator, i.e., in zones where deeper waters poor in anthropogenic $\mathrm{CO}_{2}$ communicate readily with the surface waters via upwelling and convection (Figure 1a). The subtropical regions showed smaller air-sea fluxes because surface waters

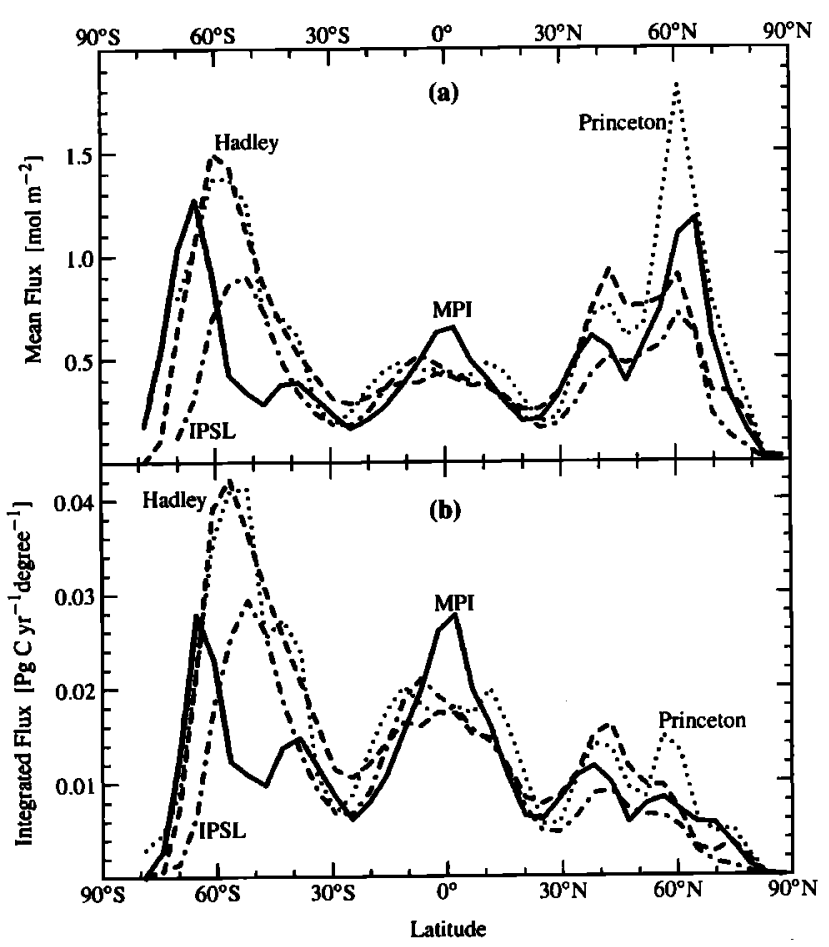

Figure 1. Zonal air-to-sea flux of anthropogenic $\mathrm{CO}_{2}$ for the global ocean in 1990, given as (a) the zonal mean (mol $\mathrm{m}^{-2}$ ) and (b) the zonal integral $\left(\mathrm{Pg} \mathrm{C} \mathrm{yr}^{-1}\right.$ degree $\left.^{-1}\right)$. 
there have had longer to equilibrate with the atmosphere. After taking ocean area into account, the Southern Ocean and the tropics dominate global ocean uptake (Figure 1b).

Despite general similarities, model simulations disagree substantially about how much and where anthropogenic $\mathrm{CO}_{2}$ is absorbed locally. The largest model differences are found for the region south of $30^{\circ} \mathrm{S}$. For that area, the simulated maximum in the zonally integrated uptake differs among models by $\sim 15^{\circ}$ in latitude. The total amount of anthropogenic $\mathrm{CO}_{2}$ transferred across the air-sea interface for the regions south of $30^{\circ} \mathrm{S}$ is $70 \%$ greater for the highest model estimate relative to the lowest. For that southern region, which makes up $31 \%$ of the surface area of the global ocean, modeled air-sea fluxes are larger than can be explained by area alone. In 1990, flux estimates there are $0.64 \mathrm{PgC} \mathrm{yr}^{-1}$ for MPI, $0.68 \mathrm{Pg} \mathrm{Cyr}^{-1}$ for IPSL, 1.10 $\mathrm{Pg} \mathrm{C} \mathrm{yr}^{-1}$ for Hadley, and $1.11 \mathrm{Pg} \mathrm{Cyr}^{-1}$ for Princeton/GFDL. Those estimates represent $35,40,46$, and $48 \%$ of each model's global uptake, respectively. Thus the models simulate that the Southern Ocean absorbs $13,29,48$, and $55 \%$ more than it would if anthropogenic $\mathrm{CO}_{2}$ uptake were determined only by ocean surface area. This larger uptake is due to enhanced mixing between surface and deep waters south of $30^{\circ} \mathrm{S}$, relative to the rest of the ocean, particularly in the Hadley and Princeton/GFDL models. Most of the differences in global uptake can be explained by discrepancies south of $30^{\circ} \mathrm{S}$.

Models differ by less in the equatorial region. Between $30^{\circ} \mathrm{S}$ and $30^{\circ} \mathrm{N}$ ( $53 \%$ of the ocean's surface), all models absorb $\sim 0.8 \mathrm{PgC} \mathrm{yr}^{-1}$. Yet because global uptake is not consistent among models, equatorial proportions relative to the total differ: $45 \%$ for the MPI and IPSL models versus $35 \%$ for the Hadley and Princeton/GFDL models. The remaining ocean north of $30^{\circ} \mathrm{N}$ represents $16 \%$ of the global ocean's surface area. Thus despite large differences among models in that region, particularly in the North Atlantic, the four models still absorb only between 15 and $20 \%$ of their global uptake there (i.e., from 0.3 to $0.5 \mathrm{PgC}^{-1}$ ). Table 3 shows the tropical versus extratropical regional breakdown: global differences clearly derive mostly from the Southern Hemisphere extratropics.

Plate 1a localizes model differences with maps of the annual mean air-sea fluxes for 1990. Differences in fluxes are caused by differences in the way models represent mixing and transport between the surface and deeper waters. Differences in upwelling and convection are crucial controls as

Table 3. Regional Anthropogenic $\mathrm{CO}_{2}$ Uptake in 1990 in $\mathrm{PgC}_{\mathrm{yr}^{-1}}$

\begin{tabular}{lccc}
\hline \multicolumn{1}{c}{ Model } & $90^{\circ}-20^{\circ} \mathrm{S}$ & $20^{\circ} \mathrm{S}-20^{\circ} \mathrm{N}$ & $20^{\circ}-90^{\circ} \mathrm{N}$ \\
\hline Princeton/GFDL & 1.24 & 0.65 & 0.56 \\
Hadley & 1.24 & 0.55 & 0.52 \\
MPI & 0.73 & 0.66 & 0.44 \\
IPSL & 0.77 & 0.59 & 0.33 \\
\hline
\end{tabular}

are the supply and loss terms due to horizontal transport. Although all models show high uptake in the Southern Ocean, near the equator, and in the North Atlantic, local uptake patterns and their intensity vary widely. The most apparent differences are in the Southern Ocean, as suggested by Figure 1. Southern Ocean $\mathrm{CO}_{2}$ uptake in the Princeton/GFDL model is concentrated in convective plumes, a well known feature of that model [Toggweiler et al., 1989a]. The Princeton/GFDL convective plumes span areas of up to $20^{\circ}$ latitudinally in the South Atlantic and South Indian Oceans. It is not exactly clear why the distribution of these plumes is so patchy. However, with essentially the same basic model, England and Hirst [1997] have shown that these large convective plumes disappear when they include seasonal forcing and a formulation for subgrid-scale mixing from Gent and McWilliams [1990]. Southern Ocean air-sea fluxes in the MPI, Hadley, and IPSL models are more homogeneous. High fluxes in the MPI model occur mainly at the northern edges of the Ross and Weddell Seas. The Hadley model spreads its high uptake more evenly throughout the Antarctic Circumpolar Current (ACC). The IPSL model's air-sea fluxes are likewise more evenly distributed across the ACC, but they are much weaker. In that region, the IPSL model exhibits a relatively high build up of anthropogenic $\mathrm{CO}_{2}$ in the surface layer. Simulations with ${ }^{14} \mathrm{C}$ and CFCs suggest that the IPSL model's surface layer in that region is too stagnant [Aumont et al., 1998; Aumont, 1998; Dutay, 1998].

Models also differ in other regions. In the North Atlantic, north of $50^{\circ} \mathrm{N}$, simulated mean air-sea fluxes in 1990 are 0.07 (IPSL), 0.10 (Hadley), 0.13 (MPI), and 0.18 (Princeton/GFDL) $\mathrm{PgC} \mathrm{Cyr}^{-1}$. In the tropics, the Pacific dominates uptake in all models. However, the regional distribution of air-sea fluxes differs substantially, despite the $\pm 10 \%$ agreement when models are integrated zonally (Table 3 ). Three models show one maximum: it is slightly north of the equator in the MPI model, yet at $\sim 10^{\circ} \mathrm{S}$ in the Hadley and IPSL models. The Princeton/GFDL model exhibits two tropical Pacific maxima, north and south of the Equator, probably owing to lack of seasonal resolution and thus a fixed ITCZ.

Maps of the anthropogenic $\mathrm{CO}_{2}$ inventory (vertical integral of the concentration) are much smoother than the 2-D air-sea flux field due to the effect of ocean circulation and mixing (Plate 1b). Ocean transport also displaces anthropogenic $\mathrm{CO}_{2}$ that enters the ocean in the high latitudes toward the lower latitudes (compare Plates 1a and 1b). For instance, all models simulate that much of the anthropogenic $\mathrm{CO}_{2}$ that enters the ocean south of $50^{\circ} \mathrm{S}$ is transported northward and is stored in the southern subtropical gyres. Yet storage of simulated inventories of anthropogenic $\mathrm{CO}_{2}$ differ a great deal, both concerning magnitude and location. The IPSL model stores very little anthropogenic $\mathrm{CO}_{2}$ south of $50^{\circ} \mathrm{S}$, whereas the other three models store large quantities. We will see that most of this difference is found in the deep water of the Southern Ocean.

During OCMIP, we were also interested in simulations of how the global air-sea flux has changed with time. Our com- 


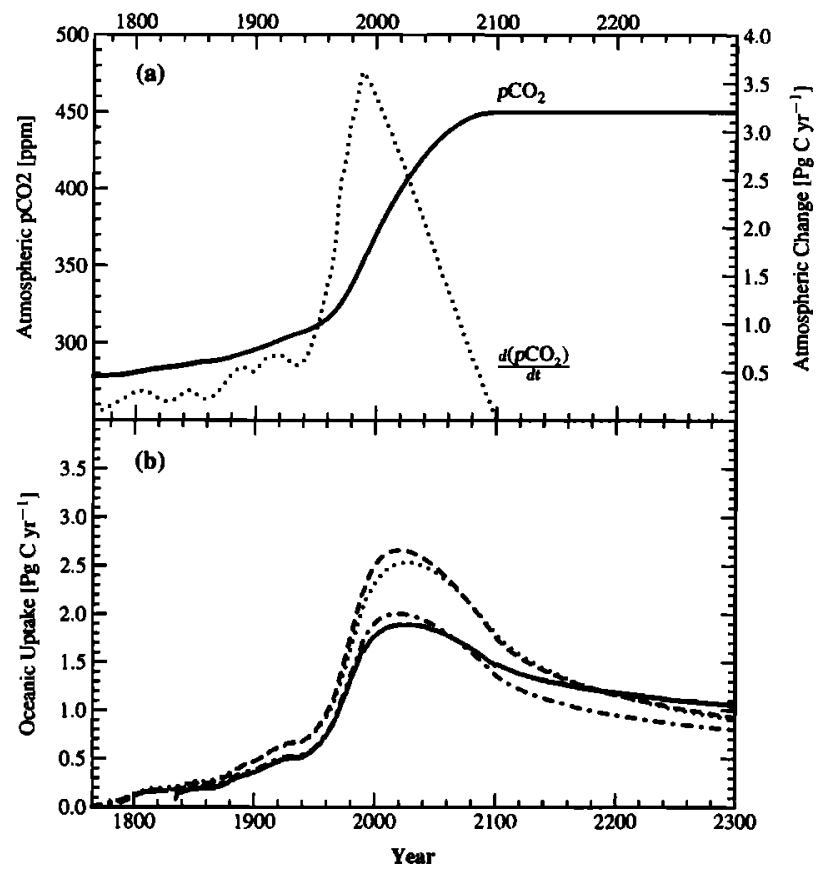

Figure 2. (a) The record of atmospheric $\mathrm{CO}_{2}$ used to force the ocean models, a spline fit to observations during $1765-$ 1990 [Enting et al., 1994] followed by IPCC scenario S450 (solid line) along with the corresponding growth rate (dotted line), and (b) the resulting air-to-sea flux of anthropogenic $\mathrm{CO}_{2}$ as simulated by the Hadley (dashed line), IPSL (dotdashed line), MPI (solid line), and Princeton/GFDL (dotted line) models.

parison concerned the historical period (1765-1990) combined with IPCC future scenario S450 (Figure 2). Models agree to within $\pm 20 \%$ for the historical period. Yet in the 1990 s, the peak in the $\mathbf{4} 450$ scenario's rate of change of atmospheric $\mathrm{CO}_{2}$ with time begins to drive larger differences. All models show that changes in the air-sea flux lags this peak due to the slow response time of the ocean. However, the Hadley and IPSL models react more rapidly to this peak in forcing, perhaps because they explicitly simulate mixed layer dynamics, whereas Princeton/GFDL and MPI do not. The subsequent divergence between MPI and IPSL models is a larger effect. Sensitivity tests made with the IPSL model suggest that some of this divergence may be caused by the choice of the advection scheme (J. C. Orr and O. Marti, Modeling ocean $\mathrm{CO} 2$ uptake: Advection matters, submitted to Ocean Modelling, 2000). We now turn toward evaluating model performance.

\section{Model Validation}

\subsection{Indirect Evaluation With Bomb ${ }^{14} \mathrm{C}$}

The bomb component of ${ }^{14} \mathrm{C}$ is of interest for evaluating models despite our inability to measure it directly and any dissimilarity with anthropogenic $\mathrm{CO}_{2}$ (Figure 3). Figure 4 shows simulated (column) inventories of bomb ${ }^{14} \mathrm{C}$, along with data-based estimates from GEOSECS. General patterns between models and data are similar, with highs in the subtropical gyres and lows in equatorial and high latitude regions. Despite general agreement though, local variability is substantial. Inventory maxima observed in the western portion of subtropical gyres are displaced to the east in simulations from the Princeton/GFDL and MPI models. This artifact is most noticeable in the Northern Pacific gyre but is also found to some degree in the Southern Hemisphere and in the Atlantic. Toggweiler et al. [1989b] attributed this problem to artificial upwelling between western boundary currents and the adjacent coast found in models where eddy diffusion is oriented only along horizontal and vertical surfaces [Veronis, 1975]; in the real ocean, mixing is thought to occur along surfaces of constant density (isopycnals) which are often inclined.

The IPSL model exhibits a nearly constant east-west distribution, but it still does not capture the western maximum as observed. In the Hadley model, the inventory maxima remain in the west as observed. We hypothesize that two enhancements to the Hadley model explain its better agreement with the observations. First, the Hadley model has included an explicit formulation for mixing along isopycnal surfaces. Thus it better captures the steeply sloping isopycnal surfaces along western margins. Hence anomalous upwelling is reduced and less model ${ }^{14} \mathrm{C}$ is displaced to the east. Second, vertical inventories are higher in the west simply because the mixed layer is deeper. This shoaling of the mixed layer from west to east is evident in the North Pacific GEOSECS section for bomb ${ }^{14} \mathrm{C}$ (Figure 5). All the OCMIP-1 models have difficulty reproducing this shoaling, but the Hadley and IPSI models seem to perform slightly better. Both models have explicit formulations for mixing within the mixed layer and below. Subsequent sensitivity tests with the IPSL model have shown that improving formulations for both isopycnal mixing and the mixed layer help resolve the anomalous symptoms revealed by the bomb ${ }^{14} \mathrm{C}$ inventory. However,

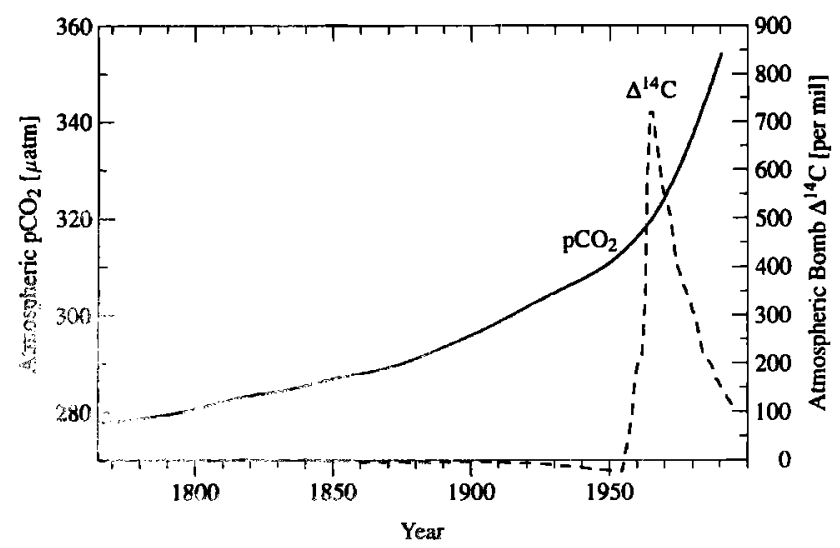

Figure 3. Atmospheric record of $\mathrm{CO}_{2}$ from a spline fit to data from the siple ice core and smoothed Mauna Loa record [Enting et al., 1994] and ${ }^{14} \mathrm{C}$ for the $20^{\circ} \mathrm{S}-20^{\circ} \mathrm{N}$ latitudinal band [Broecker et al., 1985]. 

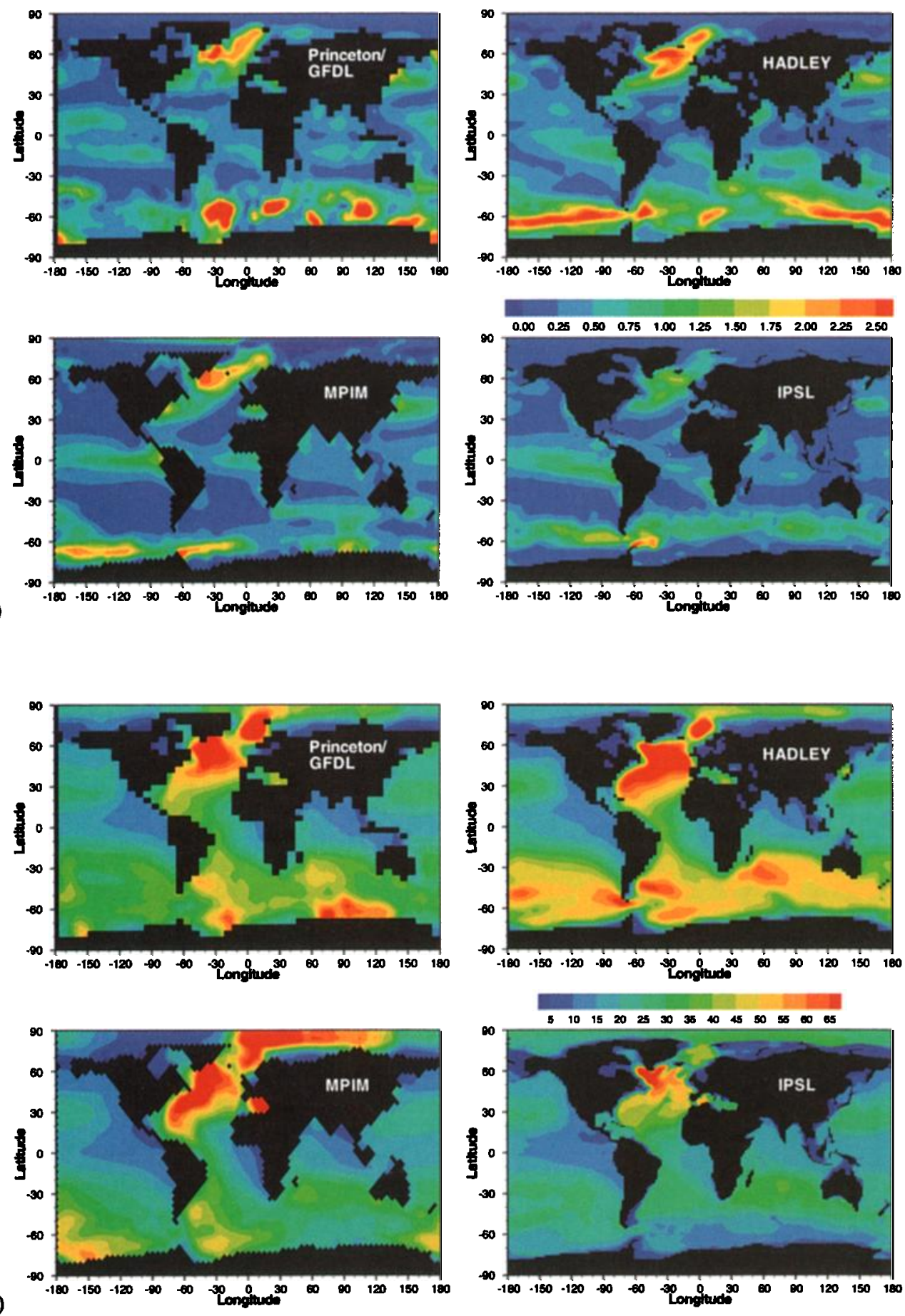

Plate 1. (a) Maps of the annual mean air-sea flux of anthropogenic $\mathrm{CO}_{2}$ in $1990\left(\mathrm{~mol} \mathrm{~m}^{-2} \mathrm{yr}^{-1}\right)$. (b) Maps of the vertical integral (inventory) of anthropogenic $\mathrm{CO}_{2}$ in $1990\left(\mathrm{~mol} \mathrm{~m}^{-2}\right)$. 

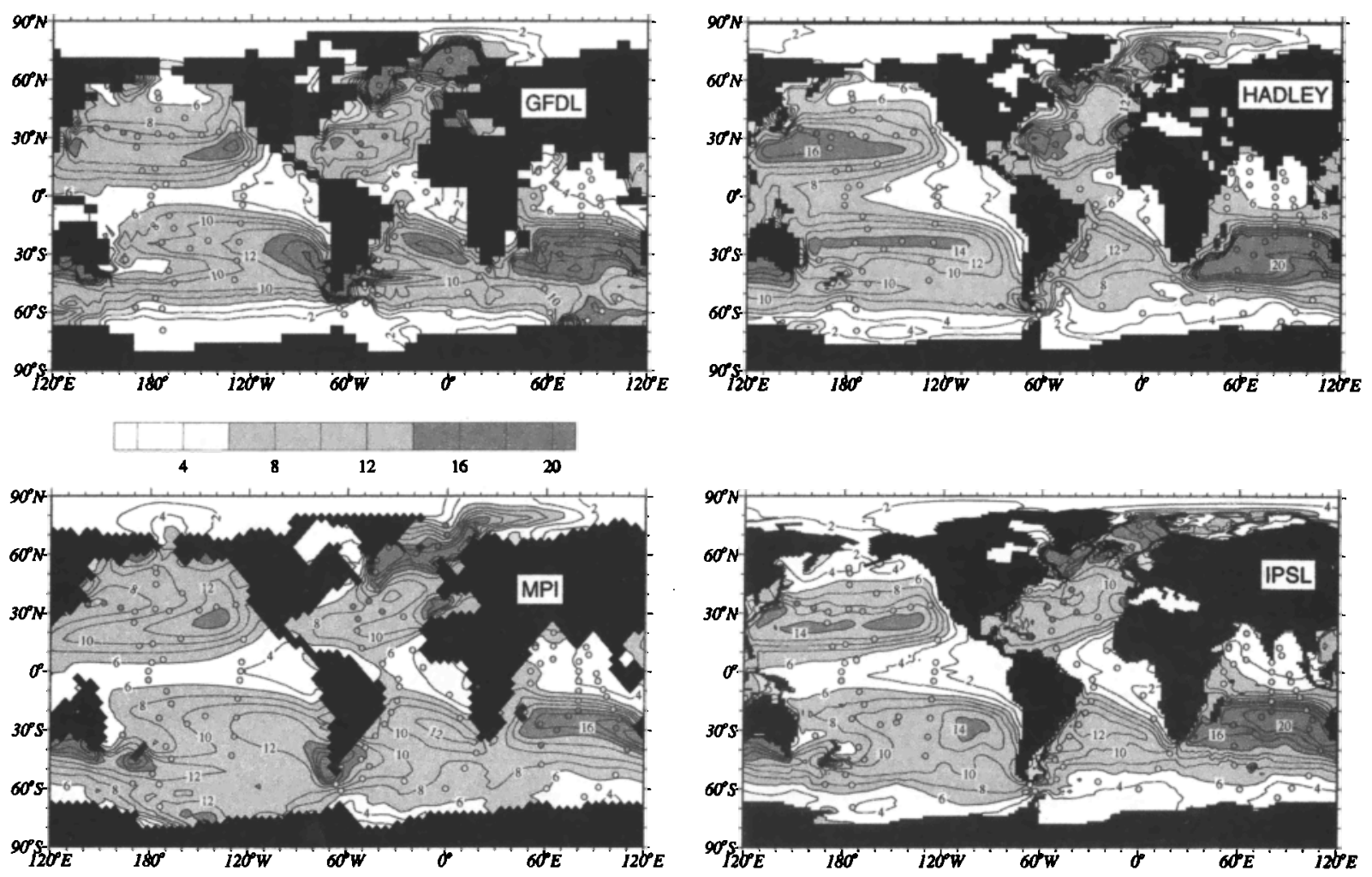

Figure 4. Bomb ${ }^{14} \mathrm{C}$ inventory (i.e., the vertical integral of the concentration) in units of $10^{9}$ atoms ${ }^{14} \mathrm{C} \mathrm{cm}^{-2}$ for the Princeton/GFDL, MPI, Hadley, and IPSL models. GEOSECS stations are marked with filled circles, shaded according to the data-based estimates of Broecker et al. [1995]. The same shading scheme is used for the data-based estimates (filled circles) and the model distributions (contour fields).

these two fixes do not offer a complete solution. For example, part of the improved east-west distribution in the Hadley model is due to surface levels of ${ }^{14} \mathrm{C}$ that are higher than observed in the west (Figure 5). These higher surface levels of ${ }^{14} \mathrm{C}$ compensate the opposite problem $\left({ }^{14} \mathrm{C}\right.$ levels which are lower than observed) in deeper waters. Hence the Hadley model's inventory in the western basin is roughly correct, but the vertical distribution is not. Other studies [Follows and Marshall, 1996; Williams et al., 1995] suggest that eddy transport, which is not explicitly included in such coarse resolution models, plays an important role.

Unfortunately, relatively few GEOSECS ${ }^{14} \mathrm{C}$ data are currently available in the Southern Ocean, where most of the simulated $\mathrm{CO}_{2}$ uptake occurs and where model $\mathrm{CO}_{2}$ simulations differ most (Figure 1). Since GEOSECS, new ${ }^{14} \mathrm{C}$ samples have been taken as part of the WOCE campaign. Recently, data-based estimates for bomb ${ }^{14} \mathrm{C}$ became available on WOCE section I6 (French section CIVA1), which was sampled in the Southern Ocean during February 1993 [Leboucher et al., 1999]. Bomb ${ }^{14} \mathrm{C}$ estimates are not yet available on other WOCE sections.

From $50^{\circ} \mathrm{S}$ to the northern limit of the WOCE I6 data, contour lines of bomb ${ }^{14} \mathrm{C}$ in the upper $700 \mathrm{~m}$ are closely spaced and inclined diagonally from the surface in the south to deeper layers in the north (Figure 6). In this region, the Hadley model agrees best in both magnitude and structure; the IPSL model shows similar agreement, but contour lines are too flat; the MPI models isolines are even flatter; and the Princeton/GFDL isolines are nearly vertical and too widely spaced. Below $700 \mathrm{~m}$ in the same region, the IPSL model agrees most closely with the data-based estimates; in the other three models, contour lines extend too deeply. South of $50^{\circ} \mathrm{S}$, data-based estimates of surface-level bomb ${ }^{14} \mathrm{C}$ are substantially lower than those simulated, particularly in the IPSL model. Furthermore, vertical penetration of data-based bomb ${ }^{14} \mathrm{C}$ is much shallower south of $50^{\circ} \mathrm{S}$, relative to that north of that limit; in sharp contrast is the opposite trend simulated by three of the models (MPI, Hadley, and Princeton). Most striking are the differences in vertical penetration of tracer south of $55^{\circ} \mathrm{S}$ : the data-based estimates above $5 \%$ are confined to the upper $500 \mathrm{~m}$; the same level of simulated bomb ${ }^{14} \mathrm{C}$ penetrates down to below $1000 \mathrm{~m}$ in the IPSL model and below $2000 \mathrm{~m}$ in the MPI, Hadley, and Princeton/GFDL models. In the latter two models, simulated bomb ${ }^{14} \mathrm{C}$ is nearly homogeneous $(20 \pm 10 \%$ ) between 300 and $1800 \mathrm{~m}$. Also, in the region south of $55^{\circ} \mathrm{S}$, the IPSL model simulates high surface concentrations and an excessive vertical gradient in the upper $500 \mathrm{~m}(\sim 90 \%$ simulated 
versus $\sim 25 \%$ from the data-based estimates). Conversely, the vertical structure is increasingly too diffuse in the MPI, Hadley, and Princeton/GFDL models. Thus it appears that real ocean uptake of bomb ${ }^{14} \mathrm{C}$ in the Southern Ocean is bracketed by the IPSL model (lower limit) and the Princeton/GFDL model (upper limit). The distribution of bomb ${ }^{14} \mathrm{C}$ along WOCE I6 appears consistent with corresponding fluxes for bomb ${ }^{14} \mathrm{C}$ that one would deduce, simplistically, from fluxes for anthropogenic $\mathrm{CO}_{2}$ (Plate 1).

Our model evaluation with bomb ${ }^{14} \mathrm{C}$ requires a regional understanding of the uncertainties that are associated with the data-based estimates. Those uncertainties are estimated to be on average of order $10 \%$ [Broecker et al., 1995]. However, uncertainties appear to be much larger for the region south of $45^{\circ} \mathrm{S}$. In that region, bomb ${ }^{14} \mathrm{C}$ inventories determined by [Leboucher et al., 1999] are up to 5 times larger than those from Broecker et al. [1995]. Efforts to better quantıfy uncertainties and improve the data-based methodology are needed, particularly in the high latitudes of the Southern Ocean.

\subsection{Bomb ${ }^{14} \mathrm{C}$ Versus Anthropogenic $\mathrm{CO}_{2}$}

Understanding the relationship between bomb ${ }^{14} \mathrm{C}$ and anthropogenic $\mathrm{CO}_{2}$ would improve our ability validate ocean carbon-cycle models. For instance, do large differences in simulated versus data-based estimates of bomb ${ }^{14} \mathrm{C}$ necessarily imply problems concerning anthropogenic $\mathrm{CO}_{2}$ ? The answer depends on our ability to constrain how the relationship between these two tracers varies, both spatially and temporally. The atmospheric input function of bomb ${ }^{14} \mathrm{C} \mathrm{oc-}$ curred essentially as a pulse, peaking in 1963; conversely, atmospheric anthropogenic $\mathrm{CO}_{2}$ has increased with an exponential growth rate following roughly a 30 -year time constant (Figure 3). GEOSECS ${ }^{14} \mathrm{C}$ observations were sampled on average only 12 years after the 1963 peak in atmospheric ${ }^{14} \mathrm{C}$; WOCE samples were taken about another 20 years later. The two tracers also differ by about a factor of 10 in the time required for the surface ocean to equilibrate with changes in the atmosphere [Broecker and Peng, 1974] Hence, even though bomb ${ }^{14} \mathrm{C}$ is also a transient tracer and
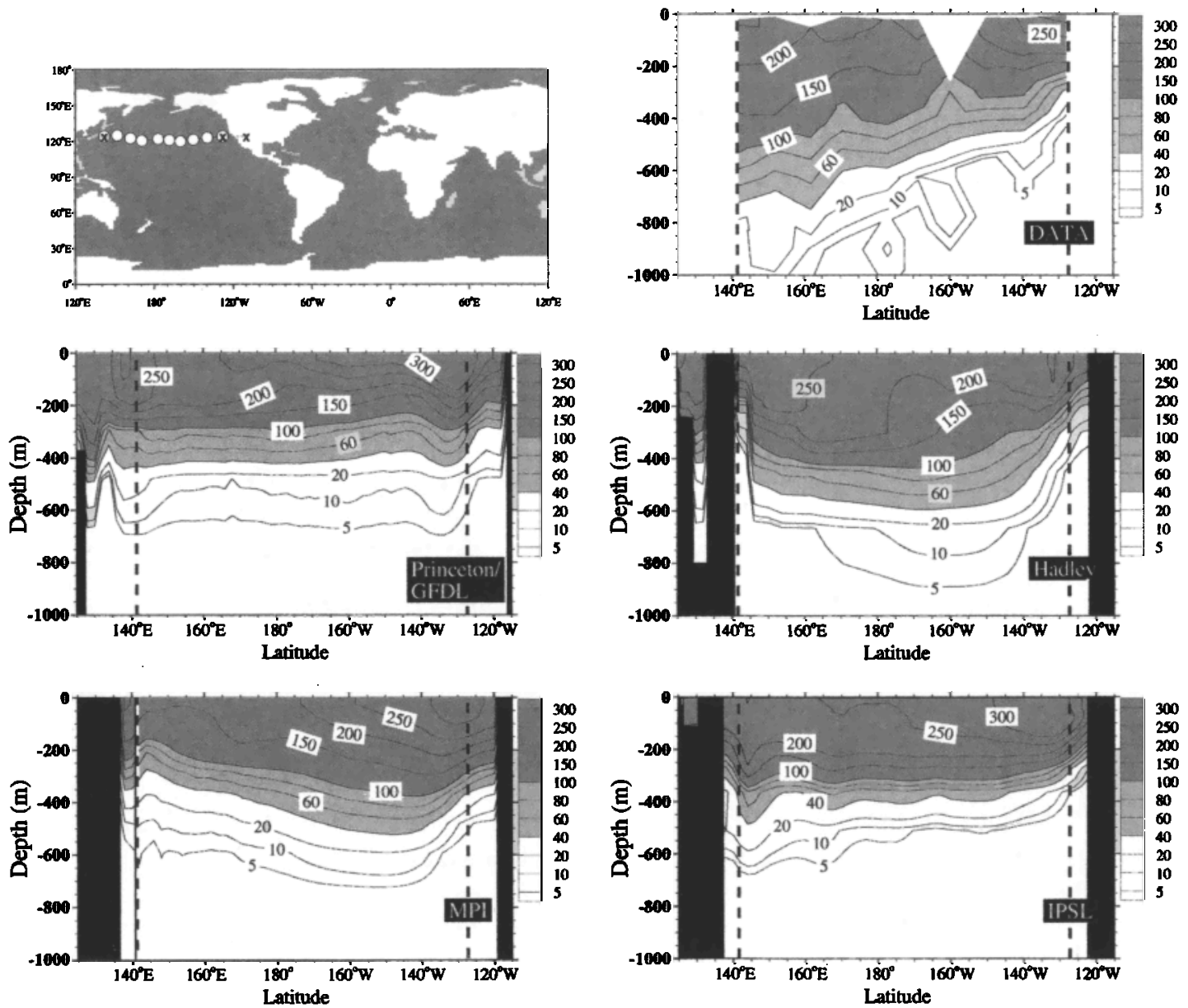

Figure 5. Bomb $\Delta^{14} \mathrm{C}$ along the GEOSECS North Pacific east-west transect. The ${ }^{14} \mathrm{C}$ data are from Östlund and Stuiver [1980], with bomb ${ }^{14} \mathrm{C}$ estimates determined by Broecker et al. [1995]. 

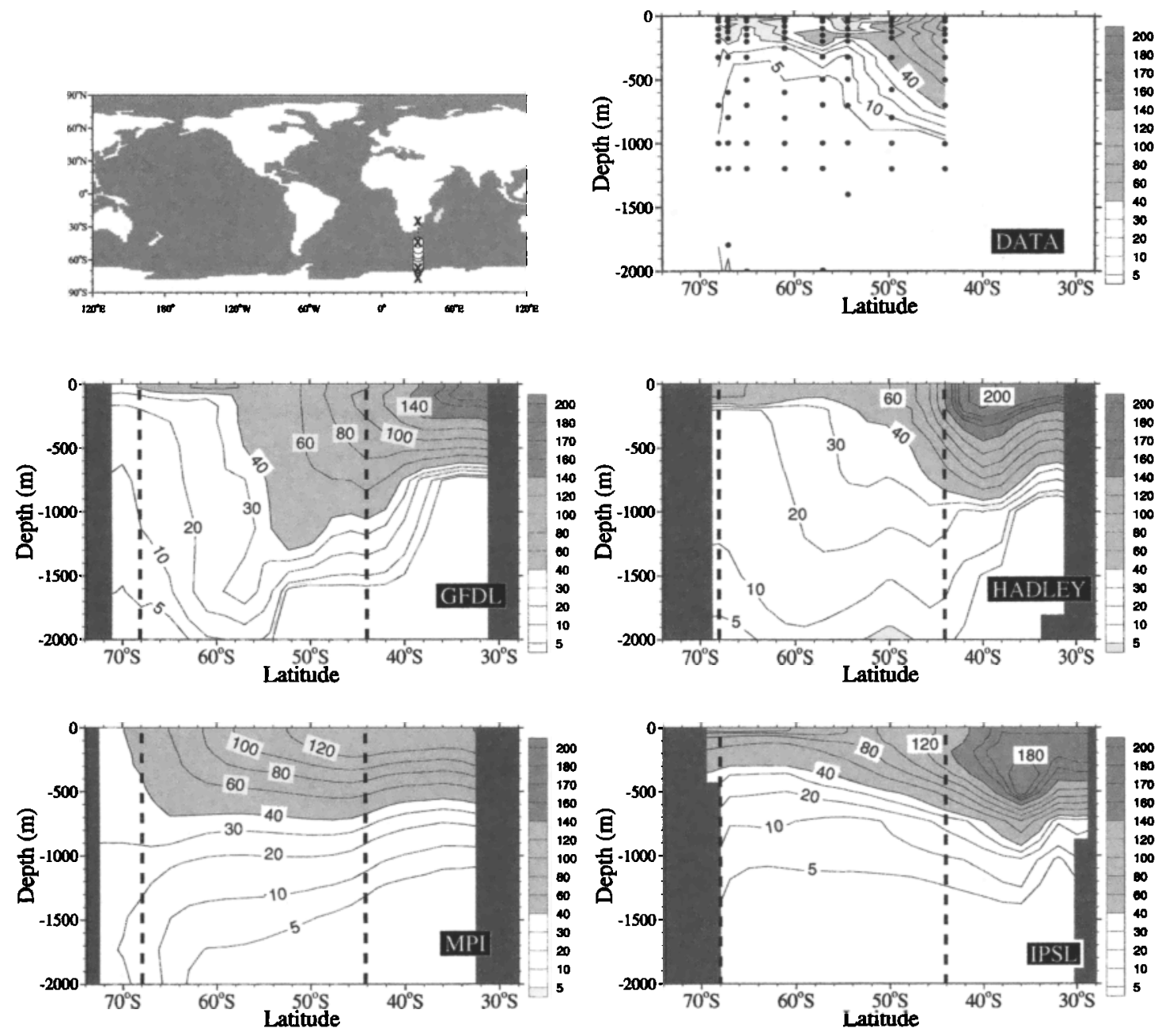

Figure 6. Bomb $\Delta^{14} \mathrm{C}$ along the WOCE section I6 (CIVA1), a north-south transect in the Southern Ocean at $30^{\circ} \mathrm{E}$ in February 1993 . Data are from recent measurements and a new method to estimate bomb $\Delta{ }^{14} \mathrm{C}$ in the Southern Ocean [Leboucher et al., 1999].

enters the ocean via air-sea exchange of $\mathrm{CO}_{2}$, it does not necessarily resemble anthropogenic $\mathrm{CO}_{2}$.

There is much scatter in the relationship between simulated inventories of bomb ${ }^{14} \mathrm{C}$ and anthropogenic $\mathrm{CO}_{2}$ during GEOSECS [Heimann and Maier-Reimer, 1996]. However, we found that the relationship between Atlantic Ocean inventories of the two tracers becomes more linear when 1990 bomb ${ }^{14} \mathrm{C}$ inventories are employed instead of those from GEOSECS (Figure 7). Such improvements with time were found in all models over most of the ocean, except south of $30^{\circ} \mathrm{S}$. With the time that has elapsed since the 1963 peak in atmospheric ${ }^{14} \mathrm{C}$, the bomb ${ }^{14} \mathrm{C}$ input function has become more comparable to that for anthropogenic $\mathrm{CO}_{2}$ (i.e., the rate of change of bomb ${ }^{14} \mathrm{C}$ with respect to time has become smoother), and ocean circulation has had a chance to spread out earlier discontinuities between these two tracers. Models disagree regarding how the bomb ${ }^{14} \mathrm{C}$ versus anthropogenic $\mathrm{CO}_{2}$ relationship may be at any given time as well as how it has changed. Still, all models suggest that an added interest of WOCE-era samples for ${ }^{14} \mathrm{C}$ is that the bomb component now resembles anthropogenic $\mathrm{CO}_{2}$ more than it did during GEOSECS.

\subsection{Direct Evaluation}

Our simulations for anthropogenic $\mathrm{CO}_{2}$ can be directly evaluated with data-based estimates for anthropogenic $\mathrm{CO}_{2}$ concentrations. Conversely, such simulations cannot be evaluated with measured $\triangle p \mathrm{CO}_{2}$ or implied total air-sea $\mathrm{CO}_{2}$ fluxes [Takahashi et al., 1999]. Both the latter contain a large, natural component, which cannot be distinguished with present methods.

We directly evaluated OCMIP-1 model simulations with recent data-based estimates for anthropogenic $\mathrm{CO}_{2}$ in the Atlantic [Gruber et al., 1996; Gruber, 1998] and Indian Oceans [Sabine et al., 1999]. The methodology used to derive anthropogenic $\mathrm{CO}_{2}$ estimates is based on measurements of carbonate system variables and transient tracer ages along surfaces of constant potential density. In the Atlantic Ocean, 
two north-south sections (Figures 8 and 9) show that three OCMIP models (Hadley, MPI, and Princeton/GFDL) overestimate data-based estimates of storage of anthropogenic $\mathrm{CO}_{2}$ in deep waters of the Southern Ocean (south of $50^{\circ} \mathrm{S}$ ). The same trend is found in the Indian sector of the Southern Ocean (Figure 10). North of $50^{\circ} \mathrm{S}$, differences are more subtle, but all three sections reveal the opposite trend. That is, simulated penetration of anthropogenic $\mathrm{CO}_{2}$ in all models is generally shallower than that estimated from the data.

Basin-wide inventories for the Atlantic Ocean, computed from the many data-based estimates from the TTO and SAVE data sets [Gruber, 1998], show substantial systematic differences relative to simulated results (Plate 2a). All models underestimate the Atlantic data-based inventory of anthropogenic $\mathrm{CO}_{2}$ between $50^{\circ} \mathrm{S}$ and $50^{\circ} \mathrm{N}$, confirming the inadequate penetration seen in the same region on both Atlantic sections (Figures 8 and 9). In that region, data-based estimates for anthropogenic $\mathrm{CO}_{2}$ are thought to have uncertainties of about $\pm 20 \%$ (see below). In the southern subtropics, the Princeton/GFDL and Hadley models underestimate data-based estimates, generally by less than $20 \%$, whereas the MPI and IPSL models underestimate data-based estimates by more than that amount. In the tropics, all models underestimate data-based estimates by more than $20 \%$. In the northern subtropics, all of the models underestimate data-based estimates, but three of them (Hadley, MPI, and Princeton/GFDL) by less than $20 \%$. The IPSL model consistently underestimates data-based inventories by more than $20 \%$ throughout most of the Atlantic basin.

That IPSL model's consistently low inventory suggests that its global air-sea flux is too low. Furthermore, given the dominance of the Southern Ocean, the IPSL air-sea fluxes

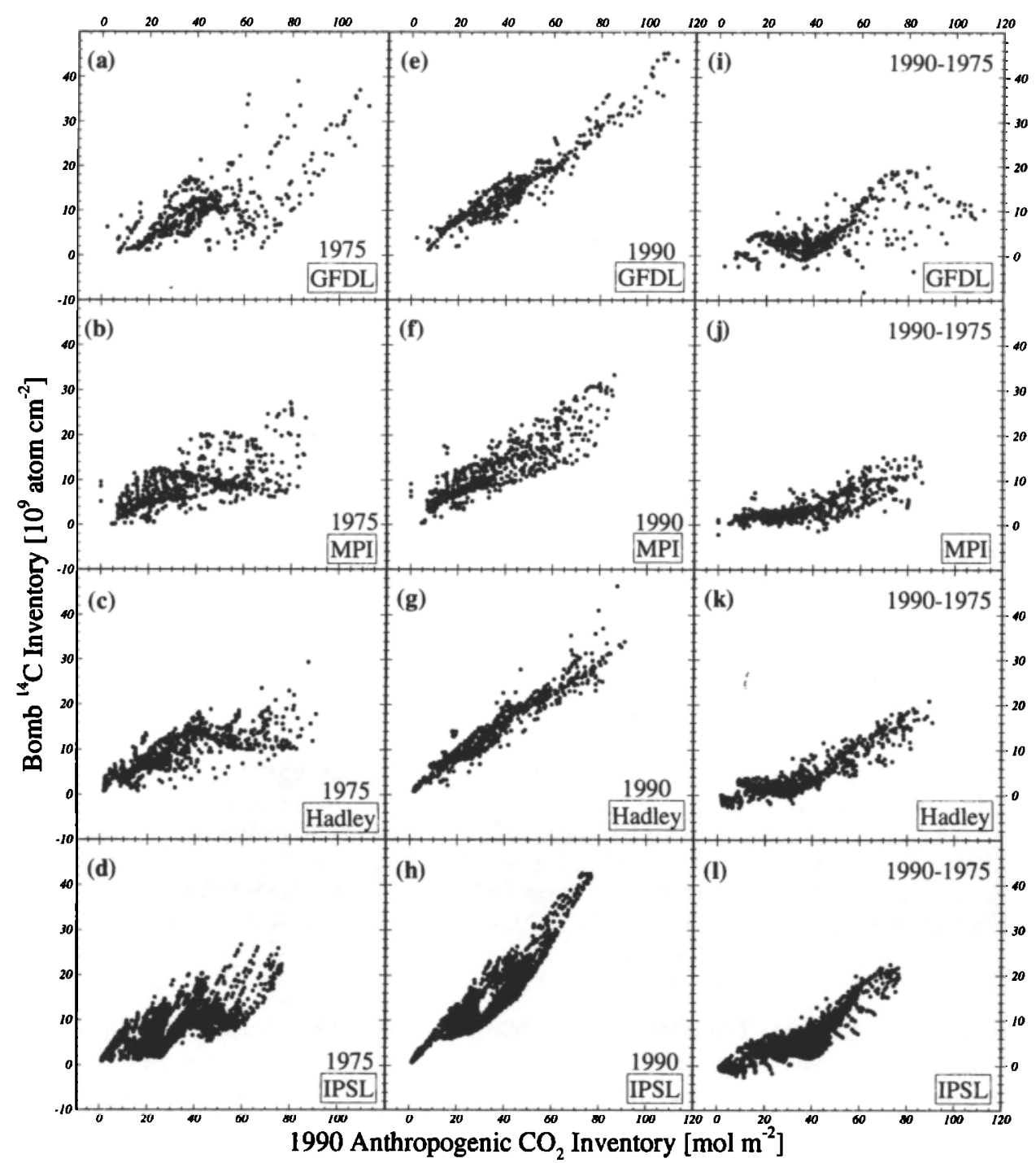

Figure 7. Comparison of modeled inventories of anthropogenic $\mathrm{CO}_{2}$ in 1990 with bomb ${ }^{14} \mathrm{C}$ inventories during (a to d) 1975, (e to h) 1990, and (i to l) $1990-1975$ for the Atlantic Ocean between $30^{\circ} \mathrm{S}$ and $70^{\circ} \mathrm{N}$. 

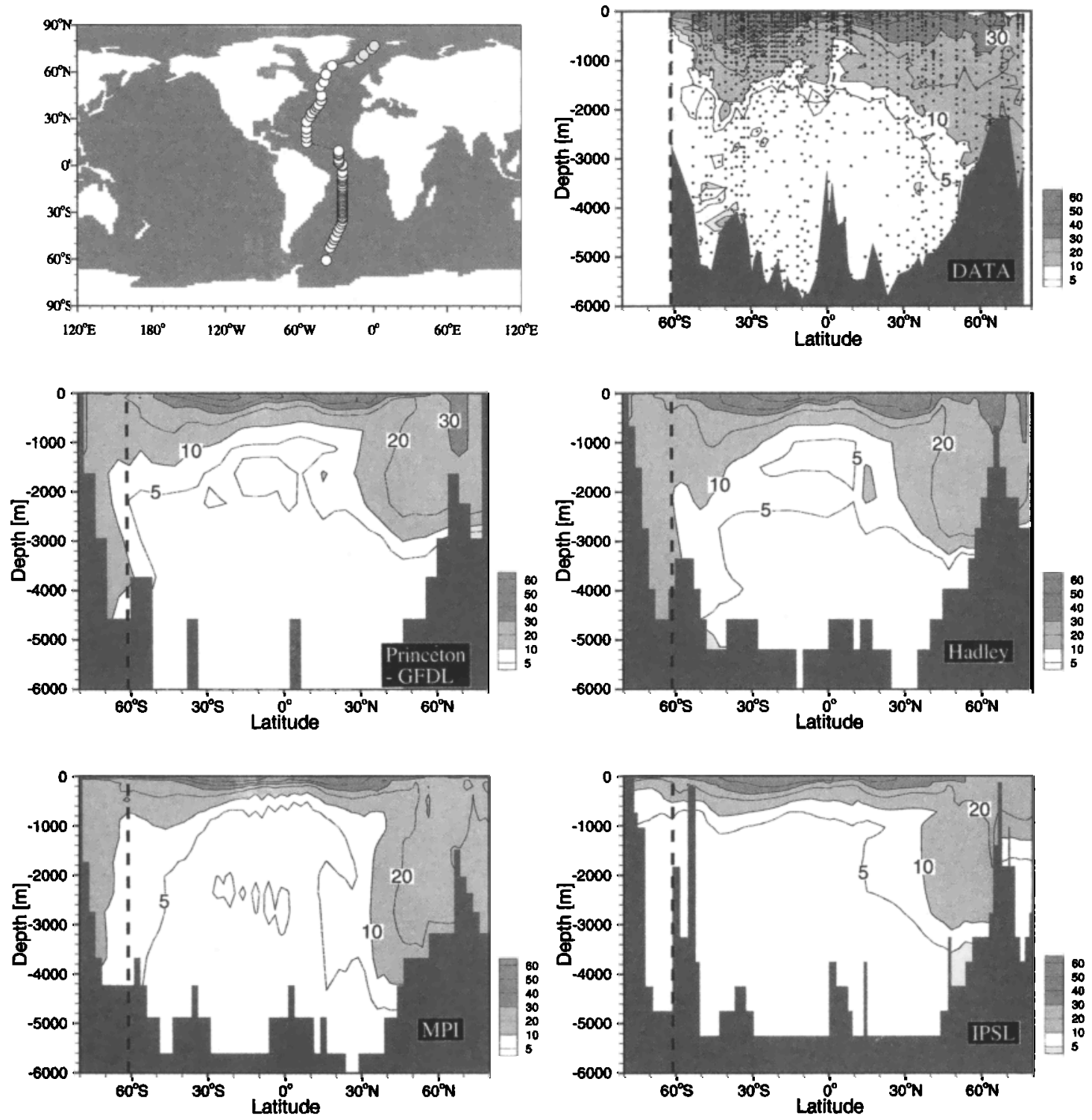

Figure 8. Data-based and model estimates of anthropogenic $\mathrm{CO}_{2}\left(\mu \mathrm{mol} \mathrm{kg}{ }^{-1}\right)$ in the western Atlantic along a transect constructed by combining stations from the Transient Tracers in the Ocean (TTO) North Atlantic Study (NAS) in 1981-1982, the TTO Tropical Atlantic Study (TAS) in 1982-1983, and the South Atlantic Ventilation Experiment (SAVE) in 1989. Data-based estimates are from Gruber [1998]. Model estimates were constructed by sampling the annual mean OCMIP-1 model distributions at the same station positions in 1982 for TTO (North Atlantic) and in 1989 for SAVE (South Atlantic).

into that region are probably also too low. The other three models also exhibit consistently low inventories in the low latitudes; however, they show consistently high inventories in the Southern Ocean. Thus their air-sea fluxes into the Southern Ocean are too high or their transport northward out of the Southern Ocean is inadequate. Data-based estimates are not without errors, however.

Both random and systematic errors are of concern when using any tracer to validate ocean models. Random errors for data-based estımates of anthropogenic $\mathrm{CO}_{2}$ have been estımated to average $\pm 9 \mu \mathrm{mol} \mathrm{kg}^{-1}$ for the Atlantic Ocean
[Gruber et al., 1996; Gruber, 1998] and $\pm 6 \mu \mathrm{mol} \mathrm{kg}^{-1}$ for the Indian Ocean [Sabine et al., 1999], based on Gaussian error propagation of uncertainties associated with samplıng and measurement as well as assumed stoichiometric ratios and end-members. A detection limit of about the same order inhibits effective model-data comparison in the deep ocean, except perhaps in the very high latitudes. The magnitude of the random error varies largely as a function of Apparent Oxygen Utilization (AOU) [Gruber et al., 1996; Wanninkhof et al., 1999]. Fortunately, random errors tend to cancel out when averaging results for basin-wide inventories. 
However, systematic errors do not cancel out. Gruber [1998] has identified three types of systematic errors: (1) the assumption of a constant $\mathrm{C}: \mathrm{O}_{2}$ ratio, when correcting for the biological contribution to measured DIC, which may contribute about a $4 \mu \mathrm{mol} \mathrm{kg}^{-1}$ error; (2) the assumption that surface ocean $p \mathrm{CO}_{2}$ has increased at the same rate as has atmospheric $p \mathrm{CO}_{2}$ which may lead to a $5 \mu \mathrm{mol} \mathrm{kg} \mathrm{kg}^{-1} \mathrm{er}-$ ror, on average, although regional errors can be much larger (see the equivalent modeled disequilibrium term $\Delta \delta p \mathrm{CO}_{2}$ [Sarmiento et al., 1992, Figures $2 \mathrm{a}$ and 4a]); and (3) the assumption that ages derived from tracers (CFC- $11,{ }^{3} \mathrm{H} /{ }^{3} \mathrm{He}$ ) represent the true ventilation age, for which uncertainties have not been quantified. Regionally, these uncertainties vary. To estimate uncertainties, Gruber [1998] and Sabine et al. [1999] altered parameters in the data-based method North of $\sim 30^{\circ} \mathrm{S}$, they estimate uncertainties of order $20 \%$, mainly due to assumption (1) above. South of $30^{\circ} \mathrm{S}$, uncertainties are potentially much larger due to assumptions (2) and (3). Unfortunately, no one has quantified uncertainties in that large southern sink region, where model simulations and data-based estimates differ most. Furthermore, uncertainty estimates for the region north of $30^{\circ} \mathrm{S}$ are approximate, being based only on a limited set of parameter-adjustment studies. Further work is needed to refine regional estimates of
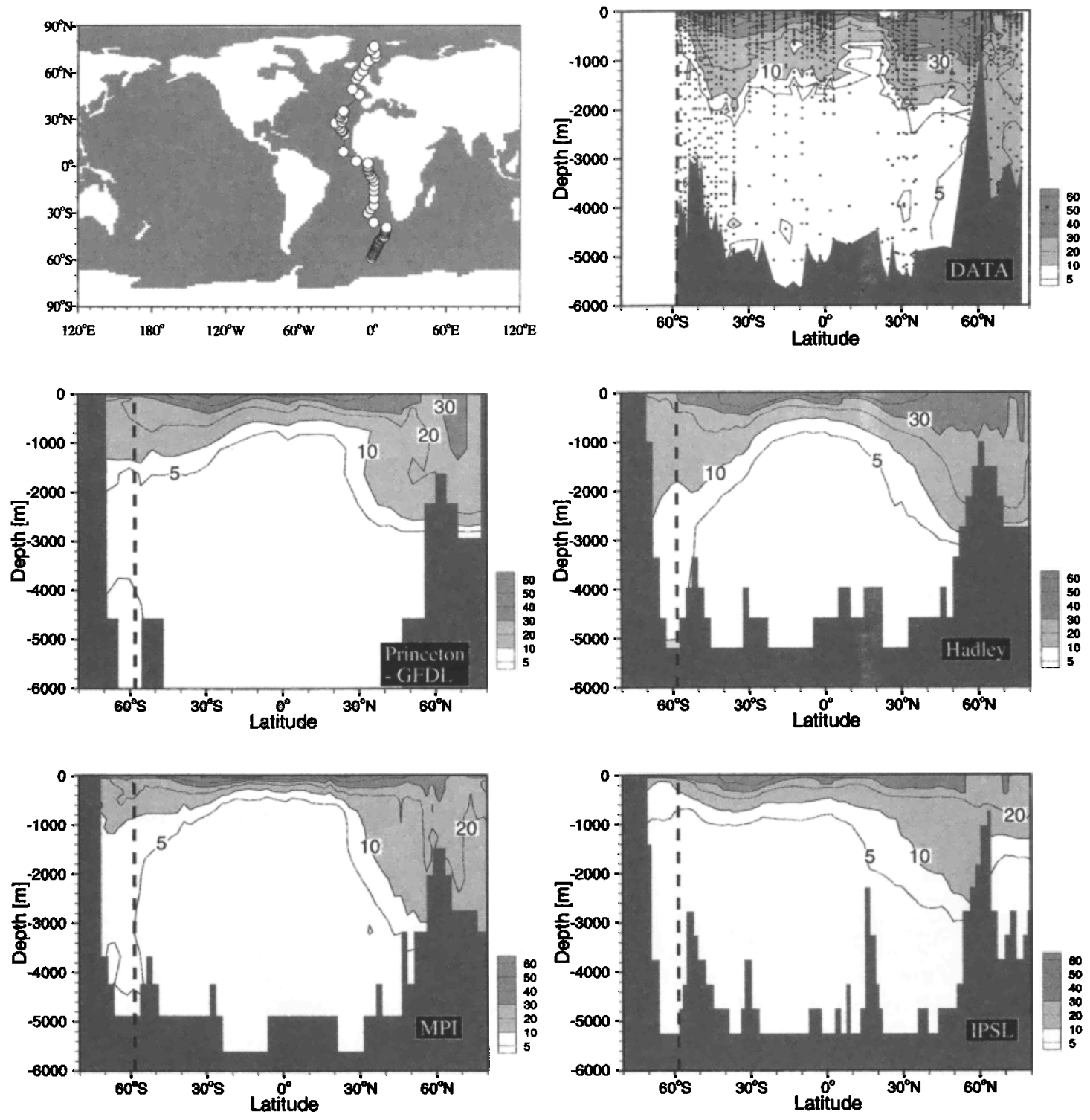

Figure 9. Data-based and model estimates of anthropogenic $\mathrm{CO}_{2}\left(\mu \mathrm{mol} \mathrm{kg}^{-1}\right)$ in the eastern Atlantic along a transect constructed by combining stations from TTO (in 1981-1982), SAVE (in 1989), and the Meteor 11/5 cruise (in 1991). Data-based estimates are from Gruber [1998]. Model estimates were constructed as described in Figure 8. 

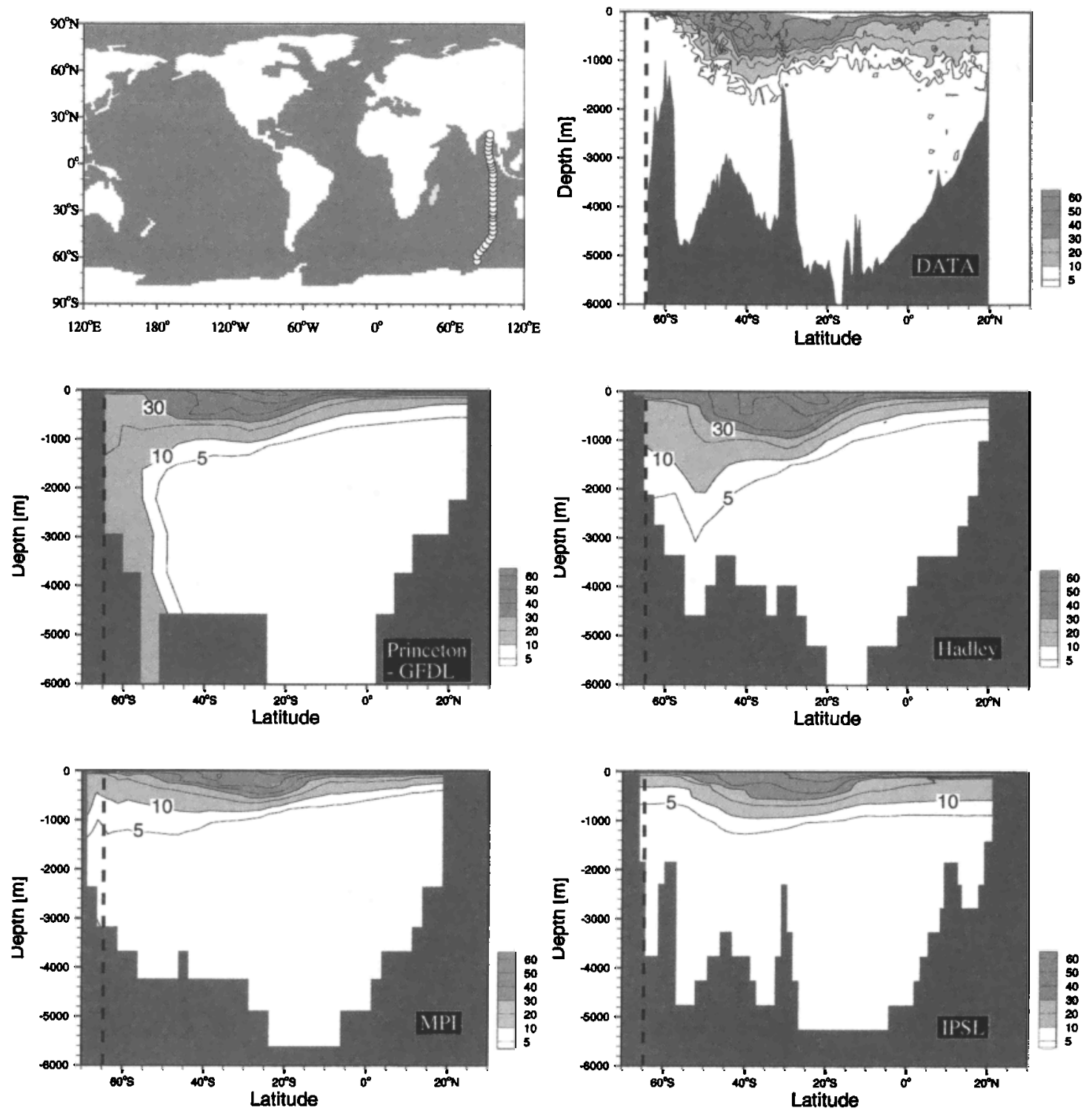

Figure 10. Data-based and model estimates of anthropogenic $\mathrm{CO}_{2}\left(\mu \mathrm{mol} \mathrm{kg}{ }^{-1}\right)$ in the east Indian Ocean along a transect constructed by combining stations from the World Ocean Circulation Experiment (WOCE) sections I8S and I9N, in 1995. Data-based estimates are from Sabine et al. [1999] who used the Gruber et al. [1996] method modified for the Indian Ocean. Model estimates were constructed by sampling, the annual mean OCMIP-1 model distributions at the same station positions, in 1995.

these uncertainties, so that modelers can fully exploit databased estimates for anthropogenic $\mathrm{CO}_{2}$ to validate models and help set limits for real ocean $\mathrm{CO}_{2}$ uptake.

Both direct and indirect evaluations help set limits on real ocean behavior. Indirect evaluation with four other tracers confirms our direct evaluation that the IPSL model provides a lower limit for the global ocean uptake of anthropogenic $\mathrm{CO}_{2}$. In the Southern Ocean, the IPSL model underestimates concentrations of CFC-11 and CFC-12 [Dutay, 1998]. In the same region, the same model simulates a vertical gradient of natural ${ }^{14} \mathrm{C}$ that is too stratified [Aumont et al, 1998; Orr, 1999a,b], suggesting that vertical penetration of transient tracers would be inadequate. Excessive stratification in the IPSL model is also indicated by bomb ${ }^{14} \mathrm{C}$ (Figure 6). Our direct evaluation suggests that IPSL model's global anthropogenic $\mathrm{CO}_{2}$ uptake has the same tendency, i.e., it is too low. As for an upper limit for global uptake, it appears that such is offered by the Princeton/GFDL model, based on our evaluation for anthropogenic $\mathrm{CO}_{2}$ and bomb ${ }^{14} \mathrm{C}$. More reliable upper and lower limits for global and regional ocean uptake and storage would be possible if uncertainties for data-based estımates could be provided at the regional scale. 

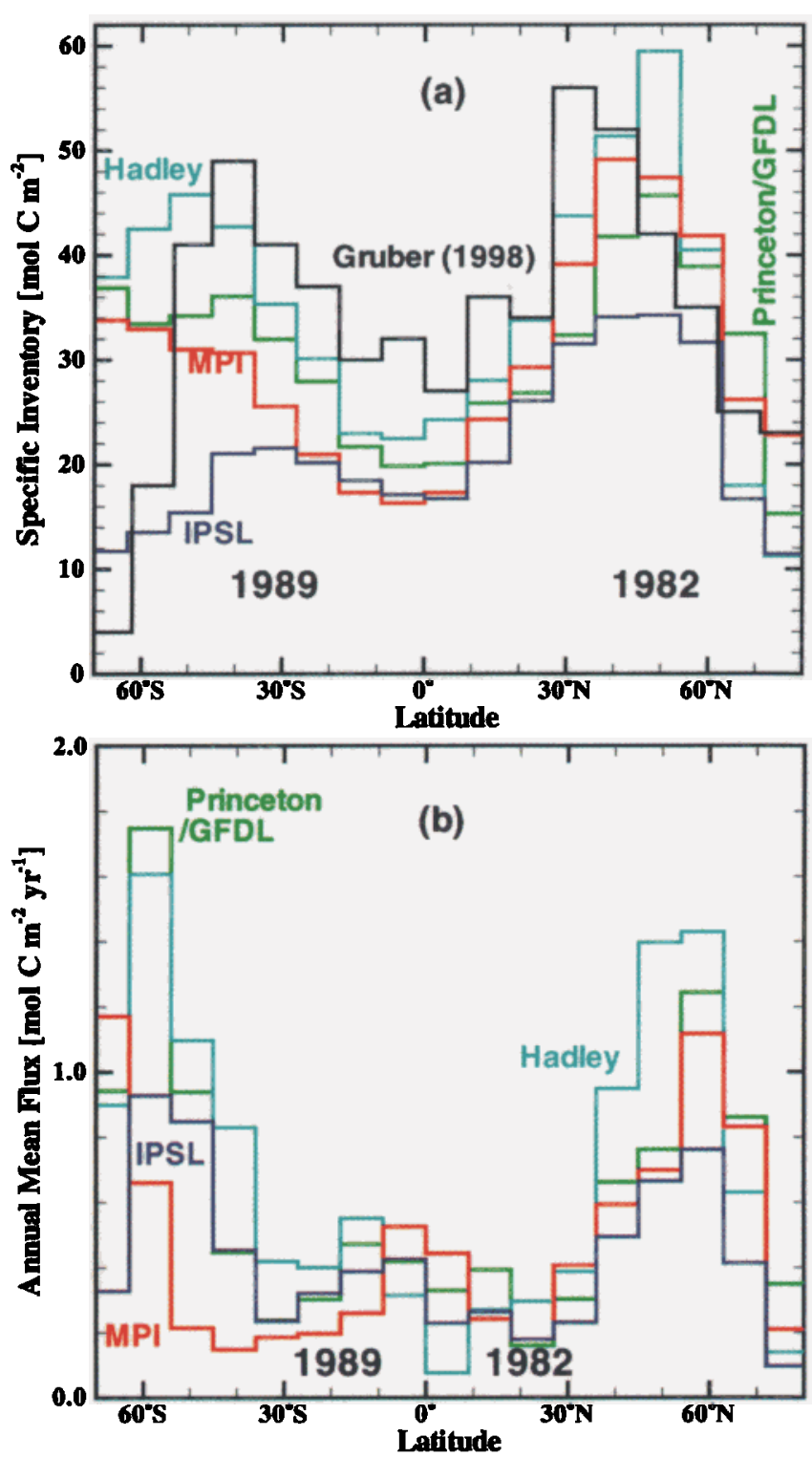

Plate 2. (a) Specific inventory of anthropogenic $\mathrm{CO}_{2}$ in the Atlantic Ocean (in mol $\mathrm{C} \mathrm{m}^{-2}$ ) according to the databased estimates of Gruber [1998] (black) and the model estimates from Princeton/GFDL (green), MPI (red), Hadley (cyan), and IPSL (blue). (b) Annual mean air-sea $\mathrm{CO}_{2}$ flux (in mol C m$~^{-2} \mathrm{yr}^{-1}$ ) simulated by the same four models. North of the equator inventories and fluxes are given for 1982 (TTO/NAS era); south of the equator they are given for 1989 (SAVE era).

\section{Conclusions}

Simulations of the recent oceanic perturbation of ${ }^{14} \mathrm{C}$ and $\mathrm{CO}_{2}$ from four ocean models have been compared within the framework of OCMIP. Estimates of global ocean uptake of anthropogenic $\mathrm{CO}_{2}$ from four 3-D models fell within $1.85 \pm 0.35 \mathrm{Pg} \mathrm{Cyr}^{-1}$ ( $\pm 19 \%$ ) for the 1980-1989 average. All models simulated that $1 / 3$ to $1 / 2$ of ocean uptake occurs south of $30^{\circ} \mathrm{S}$, a region with extensive surface area and vigorous exchange between surface and deep waters In that southern region, the magnitude of simulated anthropogenic $\mathrm{CO}_{2}$ uptake differed by nearly a factor of 2, and local patterns of uptake were very different. Agreement among global uptake estimates worsens under the IPCC future stabilization scenario $S 450$, as the southern region's uptake becomes relatively more dominant and as differences in deep water circulation come into play. Comparison of model and data-based estimates for anthropogenic $\mathrm{CO}_{2}$ suggests that three of the models may overestimate storage in the southern region. The fourth model, from IPSL, underestimates uptake in the Southern Ocean, and probably globally as well, based on evaluations with CFC's, ${ }^{14} \mathrm{C}$, and anthropogenic $\mathrm{CO}_{2}$.

At present, uncertainties for data-based estimates have not been evaluated at the regional scale, neither for anthropogenic $\mathrm{CO}_{2}$ nor for bomb ${ }^{14} \mathrm{C}$. Our poor understanding of these uncertainties limits the use of these tracers in validating ocean models. We suggest that models be used to help unravel these regional uncertainties. That is, the same data-based methodologies [Gruber, 1998; Sabıne et al., 1999; Broecker et al., 1995; Key, 1998; Leboucher et al., 1999] could be applied to the appropriate model output (e.g., $T, S$, alkalinity, CFC-11, total DIC, and total $\Delta^{14} \mathrm{C}$ ) in order to estimate the anthropogenic perturbations. Results could then be compared with estimates for anthropogenic $\mathrm{CO}_{2}$ and bomb ${ }^{14} \mathrm{C}$ which are simulated directly in the same models. More information concerning the ongoing comparison of ocean carbon-cycle models can be found at http://www.ipsl.jussieu.fr/OCMIP/.

\section{Appendix: OCMIP-1 Gas Exchange}

For OCMIP-1, the gas transfer coefficient in (4) and (6) was computed as

$$
K_{g}=\alpha k
$$

where $\alpha$ is the $\mathrm{CO}_{2}$ solubility [Weiss, 1974] and $k$ is the gas transfer velocity (also known as the piston velocity), which itself is a function of wind speed. Below we first describe the instantaneous satellite wind speed data set and then how we used that to construct monthly climatological maps of $k$ for OCMIP.

For wind speed, we used the satellite data from the first and second Special Sensor Microwave Imager (SSM/I) These instruments were mounted aboard two satellites, F08 and F10, from the U.S. Air Force Defense Meteorological Satellite Program (DMSP). They were launched on June 19, 1987, and December 1, 1990, respectively. A complete description of the SSM/I data used in this study is given by Boutin and Etcheto [1997].

From instantaneous estimates of wind speed $u$, we computed the average $\langle u\rangle$ and the standard deviation $\sigma_{u}$ for each month within each grid cell over a $2.5^{\circ} \times 2.5^{\circ}$ global map Grid cells were kept only if they contained more than 50 measurements per week. Next, we computed monthly clima- 
tologies for the 1988-1993 period: from January 1, 1988, to November 1, 1991, we used measurements from SSM/I F08; from November 1, 1991, to January 1, 1993, we used measurements from SSM/I F10. Below we describe the technique used to go from instantaneous winds to monthly climatological maps of the gas transfer velocity.

This technique can be applied to any relationship for the piston velocity which is a quadratic function of wind speed, such as that proposed by Wanninkhof [1992],

$$
k=a u^{2},
$$

where $a$ is a constant and $u$ is the instantaneous wind speed (e.g., from SSM/I). The monthly average, in angle brackets \langle\rangle , is then

$$
\langle k\rangle=a\langle u u\rangle .
$$

Furthermore, by definition of the variance

$$
\langle k\rangle=a\left(\sigma_{u}^{2}+\langle u\rangle\langle u\rangle\right),
$$

where $\sigma_{u}^{2}$ is the variance of the measured $u$ computed at $2.5^{\circ}$ and one month resolution. Finally we derived the monthly climatology of the piston velocity as

$$
\overline{\langle k\rangle}=a\left(\overline{\sigma_{u}^{2}}+\overline{\langle u\rangle^{2}}\right),
$$

where $\langle u\rangle^{2}=\langle u\rangle\langle u\rangle$ and the overbar denotes the monthly climatological average (i.e., for a given month over the full, multiple-year record).

For OCMIP, we then apply the above derivation to (5) from Wanninkhof [1992], a quadratic expression which includes chemical enhancement.

$$
\overline{\langle k\rangle}=\left[b(T)+d\left(\overline{\sigma_{u}^{2}}+\overline{\langle u\rangle^{2}}\right)\right]\left[\frac{S c(T)}{660}\right]^{-0.5},
$$

where the Schmidt number $S c(T)$ [Wanninkhof, 1992, Table A1] and the chemical enhancement term $b(T)$ [Wanninkhof, 1992, equation 6] both depend on temperature $T$. For both, we used monthly sea surface temperature maps from Levitus [1982].

Finally, we adjusted the coefficient $d$ to obtain an average value of the $\mathrm{CO}_{2}$ gas transfer coefficient $K_{g}$ of $0.061 \mathrm{~mol} \mathrm{C}$ $\mathrm{m}^{-2} \mathrm{yr}^{-1} \mu \mathrm{atm}^{-1}$ as obtained by Broecker et al. [1986] for the global mean rate based on the global inventory of oceanic bomb ${ }^{14} \mathrm{C}$. For $\alpha$ in (A1), we used surface temperatures and salinities from Levitus [1982] in the $\mathrm{CO}_{2}$ solubility formulation from Weiss [1974]. We computed the average value of $K_{g}$ over the ice-free ocean only, as determined using the climatology of fractional sea ice cover I from Walsh [1978] and Zwally et al. [1983]. Those two data sets were previously consolidated (B. Samuels, GFDL, personal communication, 1988) on the $4^{\circ} \times 5^{\circ}$ global grid of Esbensen and Kushnir [1981]. Our analysis yielded $d=0.315$; conversely with different wind speeds and variances, Wanninkhof [1992] found $d=0.304$.
It is interesting that our value for $d$ is the same as found by Wanninkhof [1992] for the case of no chemical enhancement. Wanninkhof's formulation for no chemical enhancement with the SSM/I winds and without adjusting to the global mean rate deduced from ${ }^{14} \mathrm{C}$, produces a global mean $K_{g}$ of $0.056 \mathrm{~mol} \mathrm{C} \mathrm{m}^{-2} \mathrm{yr}^{-1} \mu \mathrm{atm}^{-1}$ [Boutin and Etcheto, 1997]. Thus Wanninkhof's $b(T)$ term represents $\sim 10 \%$ of the magnitude of the mean gas exchange rate. This correction overestimates the chemical enhancement effect described by Hoover and Berkshire [1969] nearly everywhere [Boutin and Etcheto, 1995]. Overestimating chemical enhancement in this fashion is roughly equivalent to an increase of SSM/I wind speeds of $0.5-1.5 \mathrm{~m} \mathrm{~s}^{-1}$ nearly everywhere. Those differences are comparable to the precision of the SSM/I wind speed measurements [Boutin and Etcheto, 1996]. In any case, such relatively small differences have negligible impact on modeled air-sea fluxes of anthropogenic $\mathrm{CO}_{2}$ [Sarmiento et al., 1992].

Further treatment was necessary to avoid problems associated with grid transformation and inconsistencies between 2-D surface data fields from different sources (e.g., absence of satellite wind data over ocean grid points not completely covered by sea ice). Thus we first made all computations on the $2.5^{\circ} \times 2.5^{\circ}$ grid of Boutin and Etcheto [1997]. Next we filled missing values, i.e., all land grid boxes and all ocean grid boxes with $100 \%$ ice cover as determined by the the satellite SSM/I climatology. Missing values were filled with the average of adjacent ocean values (i.e., ocean grid boxes without $100 \%$ sea ice cover).

Finally, as the last step in preparation of boundary conditions, we interpolated all fields to the Levitus $1^{\circ} \times 1^{\circ}$ grid, weighting according to the relative area which each source grid box overlapped each target grid box. These climatological maps of the piston velocity $\overline{\langle k\rangle}$ are available through the OCMIP Web page (see earlier reference). Each model group interpolated these $1^{\circ} \times 1^{\circ}$ fields to their own model grid.

Acknowledgments. We thank B. Moore, M. Heimann, and D. Sahagian for discussions which helped launch and maintain OCMIP. We appreciate discussions with J. Etcheto about boundary conditions for air-sea gas exchange. We thank N. Lefevre who helped prepare OCMIP boundary conditions. We are grateful to W. S. Broecker, T.-H. Peng, and S. Sutherland for providing their complete water column bomb and natural ${ }^{14} \mathrm{C}$ estimates from GEOSECS. We thank N. Dufourg, C. Moulin, and P. Brockmann who helped analyze model output. Funding was provided by NASA, NSF (Grant ATM 96-17082), DOE, and the EC Environment and Climate Programme (Contracts ENV4-CT95-0132 and ENV4-CT97-0495). J.L.S. was supported by a grant from the NOAA Office of Global Programs (NA56GP0439) for the Carbon Modeling Consortium, and received computer support from GFDL/NOAA through the generosity of J. Mahlman. R.M.K. and C.L.S. were supported by NASA grant NAGS-6591; C.L.S. was also partially supported by the Joint Institute for the Study of the Atmosphere and Ocean (JSAO) under NOAA Cooperative Agreement NA67RJ0155 (JISAO Contribution 756 and PMEL contribution 2199). N.G. was supported by the Swiss National Science Foundation and by a Global and Climate Change fellowship from NOAA. 


\section{References}

Arakawa, A., Design of the UCLA general circulation model, numerical simulation of weather and climate, Tech. Rep. 7, Univ. of California, Dept. of Meteorology, 1972.

Aumont, O., Étude du cycle naturel du carbone dans un modèle 3D de l'océan mondial, Ph.D. thesis, Univ. Pierre et Marie Curie, Paris, 1998.

Aumont, O., J. C. Orr, D. Jamous, P. Monfray, O. Marti, and G. Madec, A degradation approach to accelerate simulations to steady state in a 3-D tracer transport model of the global ocean, Clim. Dyn., 14, 101-116, 1998.

Aumont, O., J. Orr, P. Monfray, G. Madec, and E. Maier-Reimer, Nutrient trapping in the equatorial Pacific: The ocean circulation solution, Global Biogeochem. Cycles, 13, 351-370, 1999.

Bacastow, R., and E. Maier-Reimer, Ocean-circulation model of the carbon cycle, Clim. Dyn., 4, 95-125, 1990.

Blanke, B., and P. Delecluse, Low frequency variability of the tropical Atlantic ocean simulated by a general circulation model with mixed layer physics, J. Phys. Oceanogr., 23, 1363-1388, 1993.

Boutin, J., and J. Etcheto, Estimating the chemical enhancement effect on the air-sea $\mathrm{CO}_{2}$ exchange using ERS1 scatterometer wind speeds, in Air-Water Gas Transfer, edited by B. Jähne and E. C. Monahan, pp. 827-841, AEON Verlag \& Studio, Hanau, Germany, 1995.

Boutin, J., and J. Etcheto, Consistency of geosat, SSM/I and ERS1 global surface wind speeds; comparison with in-situ data, J. Atmos. Oceanic Technol., 13, 183-197, 1996.

Boutin, J., and J. Etcheto, Long-term variability of the air-sea $\mathrm{CO}_{2}$ exchange coefficient: Consequences for the $\mathrm{CO}_{2}$ fluxes in the equatorial pacific ocean, Global Biogeochem. Cycles, 11, 453$470,1997$.

Broecker, W. S., and T.-H. Peng, Gas exchange rates between air and sea, Tellus, 26, 21-35, 1974.

Broecker, W. S., T.-H. Peng, G. Östlund, and M. Stuiver, The distribution of bomb radiocarbon in the ocean, J. Geophys. Res., 90 , 6953-6970, 1985.

Broecker, W. S., J. R. Ledwell, T. Takahashi, R. Weiss, L. Merlivat, L. Memery, T.-H. Peng, B. Jahne, and K. O. Munnich, Isotopic versus micrometeorlogic ocean $\mathrm{CO}_{2}$ fluxes, J. Geophys. Res., 91, 10,517-10,527, 1986.

Broecker, W. S., S. Sutherland, W. Smethie, T.-H. Peng, and G. Östlund, Oceanic radiocarbon: Separation of the natural and bomb components, Global Biogeochem. Cycles, 9, 263-288, 1995.

Bryan, K., A numerical method for the study of the circulation of the world ocean, J. Comput. Phys., 4, 347-376, 1969.

Bryan, K., and M. D. Cox, An approximate equation of state for numerical models of ocean circulation, J. Phys. Oceanogr., 2, 510-514, 1972.

Danabasoglu, G., J. C. McWilliams, and P. R. Gent, The role of mesoscale tracer transports in the global ocean circulation, $S c i$ ence, 264, 1123-1126, 1994.

Delecluse, P., Modelling the ocean circulation, in Long-Term Climatic Variations, NATO ASI Ser., I, 22, 73-106, 1994.

Dutay, J.-C., Influence du mélange vertical et de la couche mélangée sur la ventilation de l'océan. simulations numériques des traceurs transitoires tritium-hélium-3 et CFCs avec le modèle OPA, Ph.D. thesis, Univ. Pierre et Marie Curie, Paris, 1998.

England, M. H., and A. C. Hirst, Chlorofluorocarbon uptake in a world ocean model, 2 ., Sensitivity to surface thermohaline forcing and subsurface mixing parameterization, J. Geophys. Res., 102, 15,709-15,731, 1997.

England, M. H., and S. Rahmstorf, Senstivity of ventilation rates and radiocarbon uptake to subgrid-scale mixing in ocean models, J. Phys. Oceanogr., 29, 2802-2827, 1999.
Enting, I. G., T. M. L. Wigley, and M. Heimann, Future emissions and concentrations of carbon dioxide: key ocean/atmosphere/land analyses, Tech. pap. 31, Div. of Atmos. Res., Commonw. Sci. and Ind. Res. Org., Melbourne, Australia, 1994.

Esbensen, S. K., and Y. Kushnir, The heat budget of the global ocean: an atlas based on estimates from marine surface observations, Rep. 29, Clim. Res. Inst., Oregon State Univ., Corvallis, 1981.

Follows, M. J., and J. C. Marshall, On models of bomb ${ }^{14} \mathrm{C}$ in the ocean, J. Geophys. Res., 101, 22,577-22,582, 1996.

Gaspar, P., Y. Gregorius, and J.-M. Lefevre, A simple eddy kinetic energy model for simulations of oceanic vertical mixing tests at Station Papa and Long-Term Upper Ocean Study Site, J. Geophys. Res., 95, 16,179-16,193, 1990.

Gent, P. R., and J. C. McWilliams, Isopycnal mixing in ocean circulation models, J. Phys. Oceanogr., 20, 150-155, 1990.

Gruber, N., Anthropogenic $\mathrm{CO}_{2}$ in the Atlantic Ocean, Global Biogeochem. Cycles, 12, 165-191, 1998.

Gruber, N., J. Sarmiento, and T. Stocker, An improved method for detecting anthropogenic $\mathrm{CO}_{2}$ in the oceans, Global Biogeochem. Cycles, 10, 809-837, 1996.

Heimann, M., and E. Maier-Reimer, On the relations between the oceanic uptake of $\mathrm{CO}_{2}$ and its carbon isotopes, Global Biogeochem. Cycles, 10, 89-110, 1996.

Hoover, T. E., and D. C. Berkshire, Effects of hydration on carbon dioxide exchange across an air-water interface, J. Geophys. Res., $74,456-464,1969$.

Joos, F., J. C. Orr, and U. Siegenthaler, Ocean carbon transport in a box-diffusion versus a general circulation model, J. Geophys. Res., 102, 12,367-12,388, 1997.

Key, R. M., Early results from the WOCE radiocarbon program, paper presented at TYKKI Workshop, Japan Science and Technology Agency, Tokyo, Japan, 1998.

Kraus, E., and J. Turner, A one dimensional model of the seasonal thermocline, part II, Tellus, 19, 98-105, 1967.

Leboucher, V., J. C. Orr, P. Jean-Baptiste, P. Monfray, N. TisneratLaborde, A. Poisson, and J. C. Duplessy, Oceanic radiocarbon between antarctica and south africa along WOCE section I6 at $30^{\circ} \mathrm{E}$, Radiocarbon, 41, 51-73, 1999.

Levitus, S., Climatological atlas of the world ocean, Prof. Pap. 13, Natl. Oceanic and Atmos. Admin., Washington D.C., 1982.

Madec, G., and M. Imbard, A global ocean mesh to overcome the North Pole singularity, Clim. Dyn., 12, 381-388, 1996.

Maier-Reimer, E., Geochemical cycles in an ocean general circulation model: Preindustrial tracer distributions, Global Biogeochem. Cycles, 7, 645-677, 1993.

Maier-Reimer, E., and K. Hasselmann, Transport and storage of $\mathrm{CO}_{2}$ in the ocean-An inorganic ocean-circulation carbon cycle model, Clim. Dyn., 2, 63-90, 1987.

Maier-Reimer, E., U. Mikolajewicz, and K. Hasselmann, Mean circulation of the Hamburg LSG OGCM and its sensitivity to the thermohaline surface forcing, J. Phys. Oceanogr, 23, 731-757, 1993.

Marti, O., G. Madec, and P. Delecluse, Comment on "Net diffusivity in ocean general circulation models with non uniform grids" by F.L. Yin and I. Y. Fung, J. Geophys. Res., 97, 12,763-12,766, 1992.

Murnane, R. J., J. L. Sarmiento, and C. L. Quéré, The spatial distribution of air-sea $\mathrm{CO}_{2}$ fluxes and the interhemispheric transport of carbon by the oceans, Global Biogeochem. Cycles, 13, 287306, 1999.

Orr, J. C., Accord between ocean models predicting uptake of anthropogenic $\mathrm{CO}_{2}$, Water, Air, Soil Pollut., 70, 465-481, 1993.

Orr, J. C., Ocean Carbon-Cycle Model Intercomparison Project (OCMIP): Phase 1 (1995-1997), GAIM Rep. 7, GAIM Office, EOS, Univ. New Hampshire, Durham, 1999a. 
Orr, J. C., Ocean circulation and the Ocean Carbon-Cycle Model Intercomparison Project, Int. WOCE Newsletter, 35, 24-25, 1999b.

Östlund, G., and M. Stuiver, GEOSECS Pacific radiocarbon, $R a$ diocarbon, 22, 25-53, 1980.

Redi, M. H., Oceanic isopycnal mixing by coordinate rotation, $J$. Phys. Oceanogr., 12, 1154-1158, 1982.

Sabine, C. L., R. M. Key, C. Goyet, K. M. Johnson, F. J. Millero, A. Poisson, J. L. Sarmiento, D. W. R. Wallace, and C. D. Winn, Anthropogenic $\mathrm{CO}_{2}$ inventory of the Indian Ocean, Global Biogeochem. Cycles, 13, 179-198, 1999.

Sarmiento, J. L., J. C. Orr, and U. Siegenthaler, A perturbation simulation of $\mathrm{CO}_{2}$ uptake in an ocean general circulation model, $J$. Geophys. Res., 97, 3621-3645, 1992.

Sarmiento, J. L., R. Murnane, and C. Le Quéré, Air-sea $\mathrm{CO}_{2}$ transfer and the carbon budget of the North Atlantic, Philos. Trans. $R$. Soc. London, Ser. B, 348, 211-219, 1995.

Sarmiento, J. L., P. Monfray, E. Maier-Reimer, O. Aumont, R. Murnane, and J. C. Orr, Sea-air $\mathrm{CO}_{2}$ fluxes and carbon transport: A comparison of three ocean general circulation models, Global Biogeochem. Cycles, in press, 2000.

Schimel, D., I. G. Enting, M. Heimann, T. M. L. Wigley, D. Raynaud, D. Alves, and U. Siegenthaler, $\mathrm{CO}_{2}$ and the carbon cycle, in Climate Change 1994, edited by J. T. Houghton et al., pp. 35-71, Cambridge Univ. Press, New York, 1995.

Siegenthaler, U., and J. L. Sarmiento, Atmospheric carbon dioxide and the ocean, Nature, 365, 119-125, 1993.

Smolarkiewicz, K. P., and T. L. Clark, The multidimensional positive definite advection transport algorithm: further development and applications, J. of Comp. Phys., 67, 396-438, 1986.

Takahashi, T., R. H. Wanninkhof, R. A. Feely, R. F. Weiss, D. W. Chipman, N. Bates, J. Olafsson, C. Sabine, and S. C. Sutherland, Net sea-air $\mathrm{CO}_{2}$ flux over the global oceans: An improved estimate based on the sea-air $\mathrm{pCO}_{2}$ difference, paper presented at 2nd International Symposium, $\mathrm{CO}_{2}$ in the Oceans-The 12th Global Environment, Cent. Global Env. Res., N. Inst. Env. Stud., Tsukuba, Japan, 1999.

Taylor, N. K., Seasonal uptake of anthropogenic $\mathrm{CO}_{2}$ in an ocean general circulation model, Tellus Ser. B, 47B, 145-169, 1995.

Toggweiler, J. R., K. Dixon, and K. Bryan, Simulations of radiocarbon in a coarse resolution world ocean model, $1 .$, Steady state prebomb distributions, J. Geophys. Res., 94, 8217-8242, 1989a.

Toggweiler, J. R., K. Dixon, and K. Bryan, Simulations of radiocarbon in a coarse resolution world ocean model, 2., Distributions of bomb-produced carbon 14, J. Geophys. Res., 94, 8243-8264, $1989 \mathrm{~b}$.

Veronis, G., The role of models in tracer studies, in Numerical Models of the Ocean Circulation, pp. 133-146, Nat. Acad. of Sci., Washington, D.C., 1975.

Walsh, J., A data set on northern hemisphere sea ice extent, 1953-
1976, Glaciological Data Report GD-2, World Data Cent. A for Glaciol. [Snow and Ice], Boulder, Colo., 1978.

Wanninkhof, R., Relationship between wind speed and gas exchange over the ocean, J. Geophys. Res., 97, 7373-7382, 1992.

Wanninkhof, R., S. C. Doney, T.-H. Peng, J. L. Bullister, K. Lee, and R. A. Feely, Comparison of methods to determine the anthropogenic $\mathrm{CO}_{2}$ invasion into the Atlantic Ocean, Tellus Ser. B, 51B, 511-530, 1999.

Watson, R. T., H. Rodhe, H. Oeschger, and U. Siegenthaler, Greenhouse gases and aerosols, in Climate Change, The IPCC Scientific Assessment, edited by J. T. Houghton, G. J. Jeankins, and J. J. Ephraums, pp. 1-40, Cambridge Univ. Press, New York, 1990.

Weiss, R. F., Carbon dioxide in water and seawater: the solubility of a non-ideal gas, Mar. Chem., 2, 203-215, 1974.

Williams, R. G., M. A. Spall, and J. C. Marshall, Does Stommel's mixed layer "Demon" work, J. Phys. Oceanogr., 25, 3089-3102, 1995.

Yin, F. L., and I. Y. Fung, Net diffusivity in ocean general circulation models with nonuniform grids, J. Geophys. Res., 96, 10,773-10,776, 1991.

Zwally, H. J., J. Comiso, C. Parkinson, W. Campbell, F. Carsey, and P. Gloerson, Antarctic Sea Ice, 1973-1976: Satellite Passive Microwave Observations, NASA, Washington D.C., 1983.

J. Boutin, LODyC, Université Paris VI, 4 Place Jussieu, Tour 14, 2eme etage, F-75252 Paris Cedex 05, France. (boutin@lodyc.jussieu.fr)

N. Gruber and J. L. Sarmiento, AOS Program, Princeton University, Sayre Hall, P.O. Box CN710, Forrestal Campus, Princeton, NJ 08542-0710. (gruber@splash.princeton.edu; jls@princeton.edu)

R. M. Key, Department of Geosciences, Princeton University, Guyot Hall, Princeton, NJ 08544. (key@princeton.edu)

C. Le Quéré, Max-Planck-Institut für Biogeochemie, Carl-ZeissPromenade 10, 07745 Jena, Germany. (lequere@bgc-jena.mpg.de)

E. Maier-Reimer and U. Mikolajewicz, Max Planck Institut fr Meteorologie, Bundestrasse 55, Hamburg, Germany. (maierreimer@dkrz.de; mikolajewicz@dkrz.de)

P. Monfray and J. C. Orr, LSCE, CEA Saclay, Bât. 709, L'Orme des Merisiers, F-91191 Gif-sur-Yvette Cedex, France. (monfray@cea.fr; orr@cea.fr)

J. Palmer and N. K. Taylor, Hadley Centre, UK Meteorological Office, London Rd., Bracknell RG12 2SZ, England, UK.

C. L. Sabine, Joint Institute for the Study of Atmosphere and Ocean, University of Washington, c/o NOAA/PMEL, 7600 Sand Point Way NE, Seattle, WA 98115. (sabine@pmel.noaa.gov)

J. R. Toggweiler, Geophysical Fluid Dynamics Laboratory/NOAA, P.O. Box 308, Princeton, NJ 08542. (jrt@gfdl.gov)

(Received March 3, 2000; revised July 15, 2000; accepted July 28, 2000.) 